DOI : $10.24850 / \mathrm{j}-$ tyca-2022-01-09

Artículos

\title{
Determinación de parámetros de diseño de rompeolas sumergidos mediante simulación numérica para su empleo en playas
}

\section{Determination of design parameters of submerged breakwater by means of numeric simulation for their employment in beaches}

Kenia Hernández-Valdés ${ }^{1}$, ORCID: https://orcid.org/0000-0003-03732592

Luis Fermín Córdova-López², ORCID: https://orcid.org/ 0000-00018175-6819

${ }^{1}$ Inversiones Gamma S.A, La Habana, Cuba, kenia@gamma.com.cu 2Universidad Tecnológica de La Habana, Cuba, cordova@tesla.cujae.edu.cu

Autora para correspondencia: Kenia Hernández-Valdés, kenia@gamma.com.cu

\section{Resumen}


La necesidad de implementar soluciones que garanticen la protección y recuperación de la zona costera hace que se evalúe el empleo de rompeolas sumergidos como una variante viable de aplicación, pues estas obras contribuyen a la conservación de las condiciones naturales, estéticas y paisajísticas de las playas, lo que forma parte del producto turístico que se comercializa. Sin embargo, los parámetros que intervienen en su diseño funcional no están muy bien establecidos y llegan a propiciar en muchos casos patrones de circulación en las corrientes que contribuyen a la erosión y la degradación de la costa. El presente trabajo forma parte del desarrollo del Sistema de Ingeniería Costera y Marítima (SICOM), que lleva a cabo el Centro de Investigaciones Hidráulicas de la Universidad Tecnológica de La Habana, centrado en simular tanto los cambios hidrodinámicos como morfológicos que ocurren en las playas cubanas ante la presencia de rompeolas sumergidos, y en obtener los parámetros de diseño para el empleo de estas obras en la mitigación de la erosión de las playas, utilizando modelos numéricos como herramientas predictivas.

Palabras clave: rompeolas sumergidos, cambios morfológicos, modelos numéricos.

\section{Abstract}

The necessity to implement solutions that guarantee the protection and recovery of the coastal area makes that the submerged breakwater employment is evaluated as a viable variant of application because these works contribute to the conservation of the natural and aesthetic 
conditions of the beaches, which is part of the tourist product that is marketed. However, the parameters that intervene in their functional design are not very well established, propitiating in many cases circulation patterns in the currents that contribute to the erosion and the degradation of the coast. The present work is part of the development of the Coastal and Marine Engineering System (SICOM) that carries out the Hydraulic Investigations Center of the Technological University of Havana, centered in to simulate so much the hydrodynamic changes as morphological that happen in the Cuban beaches before the presence of submerged breakwater, and in obtaining the design parameters for the employment of these works in the mitigation of the erosion of the beaches, using numeric models as predictive tools.

Keywords: Submerged breakwater, morphological changes, numeric models.

Recibido: 22/05/2018

Aceptado: $17 / 01 / 2021$

\section{Introducción}


La zona costera constituye un recurso de incalculable valor económico y social que el hombre ha venido utilizando desde épocas remotas, y que sufre en los últimos años un proceso de erosión significativa y generalizada, como consecuencia en gran medida de acciones antrópicas que interrumpen el transporte litoral de sedimentos y el urbanismo masivo, entre otros. Esta problemática se acentúa aún más bajo el contexto del cambio climático global, en el cual numerosos factores asociados con el calentamiento atmosférico y el ascenso del nivel medio del mar han dado lugar a un aumento de la incidencia e intensidad de las tormentas que afectan el área geográfica, así como a la generalización de los problemas erosivos, lo que trae aparejado grandes daños económicos, la pérdida significativa de espacios y riesgos extremos por inundaciones costeras.

La necesidad de implementar soluciones que garanticen la protección de la zona litoral hace que se considere el empleo de rompeolas sumergidos como una variante viable de aplicación, pues estas obras contribuyen a la conservación de las condiciones naturales, estéticas y paisajísticas de las playas; además, tienen un menor costo económico al requerir menos volumen de materiales. Sin embargo, los parámetros que intervienen en su diseño funcional no están muy bien establecidos, por lo que si no son correctamente modeladas y diseñadas pueden propiciar patrones de circulación en las corrientes que contribuyan a la erosión y degradación de la costa (Ranasinghe, Larson, \& Savioli, 2010).

En este sentido, el trabajo muestra la aplicación del Sistema de Ingeniería Costera y Marítima (SICOM) que desarrolla el Centro de Investigaciones Hidráulicas (Hernández \& Córdova, 2015; Hernández \& 
Córdova, 2016; Córdova, Hernández, \& Benítez, 2017), centrado en simular tanto los cambios hidrodinámicos como morfológicos que ocurren en las playas cubanas ante la presencia de rompeolas sumergidos, y en obtener por primera vez en el país los parámetros de diseño para el empleo de estas obras en la mitigación de la erosión de las playas, utilizando el modelo XBeach (Roelvink et al., 2009), por ser capaz de simular procesos tanto hidrodinámicos como morfológicos en playas, playas con dunas y playas barrera en condiciones de alta energía. Este modelo ha sido extendido, aplicado y validado por sus autores con una serie de casos analíticos, de laboratorio y con mediciones de campo en gran número de playas bordeando los mares regionales de la Unión Europea. Como parte del trabajo, previamente se calibra y valida la hidrodinámica del modelo, empleando los resultados obtenidos de la modelación física realizada en el laboratorio de la Universidad de Nápoles, Italia, para el caso del diseño de rompeolas en el malecón tradicional de La Habana.

\section{Materiales y métodos}

El diseño de la investigación se realizó en dos etapas: 


\section{Calibración y validación del modelo XBeach. La calibración y} validación de la morfología del modelo aparece reflejada en Hernández y Córdova (2016), donde se establece como modelo de disipación de energía la opción break 1; como índice de rompiente gamma, el valor de 0.4; el valor de gammáx 2 como limitador del modelo, y como pendiente crítica sumergida wets/p el valor de 0.3 .

La validación de la hidrodinámica se realizó reproduciendo con el XBeach la modelación realizada en el laboratorio de la Universidad de Nápoles como parte de la campaña en modelos físicos dirigida al diseño de rompeolas en el malecón tradicional de La Habana. Para ello, se compararon los resultados obtenidos de la modelación numérica con los valores medidos por los sensores en el tanque de oleaje del modelo físico, donde se reprodujo el perfil característico del malecón tradicional a escala 1:30 en un canal de $1.56 \mathrm{~m}$ de ancho y $18.37 \mathrm{~m}$ de largo construido dentro del tanque de oleaje aleatorio Random Wave Tank (RATA). Los experimentos se hicieron con dos rompeolas: uno de cresta ancha con su bordo libre al nivel medio del agua y otro de cresta estrecha que emerge a $0.80 \mathrm{~m}$. Los coeficientes de determinación obtenidos fueron de 0.86 para las alturas de ola significativas y de 0.97 para el setup del oleaje, demostrando que el modelo XBeach es capaz de simular correctamente la hidrodinámica que se genera ante la presencia de rompeolas sumergidos.

\section{Establecimiento del modelo y simulación de las variables}

hidrodinámicas y morfológicas. Se estableció una malla de trabajo no equidistante utilizando perfiles medidos en la playa de Varadero a los que se les determinó el perfil de equilibrio empleando la expresión dada por 
Tecnología y

Ciencias $₫$ Agua
2022, Instituto Mexicano de Tecnología del Agua

Open Access bajo la licencia CC BY-NC-SA 4.0

(https://creativecommons.org/licenses/by-nc-sa/4.0/)

García (2005) para el parámetro de escala del sedimento, la cual presenta un mejor ajuste para caracterizar las condiciones de las playas biogénicas cubanas (Figura 1). La malla abarca un área de $492000 \mathrm{~m}^{2}$ comprendida por $615 \mathrm{~m}$ en dirección perpendicular a la costa con resolución de $5 \mathrm{~m}$ (123 nodos) y $800 \mathrm{~m}$ a lo largo de la costa con resolución de $10 \mathrm{~m}$ (80 nodos), con profundidades que parten desde la isobata de $8 \mathrm{~m}$ hasta alcanzar cotas de $3 \mathrm{~m}$ por encima del nivel medio del mar en la zona de dunas, lo que lo permitió visualizar los procesos ocurridos en cada simulación.

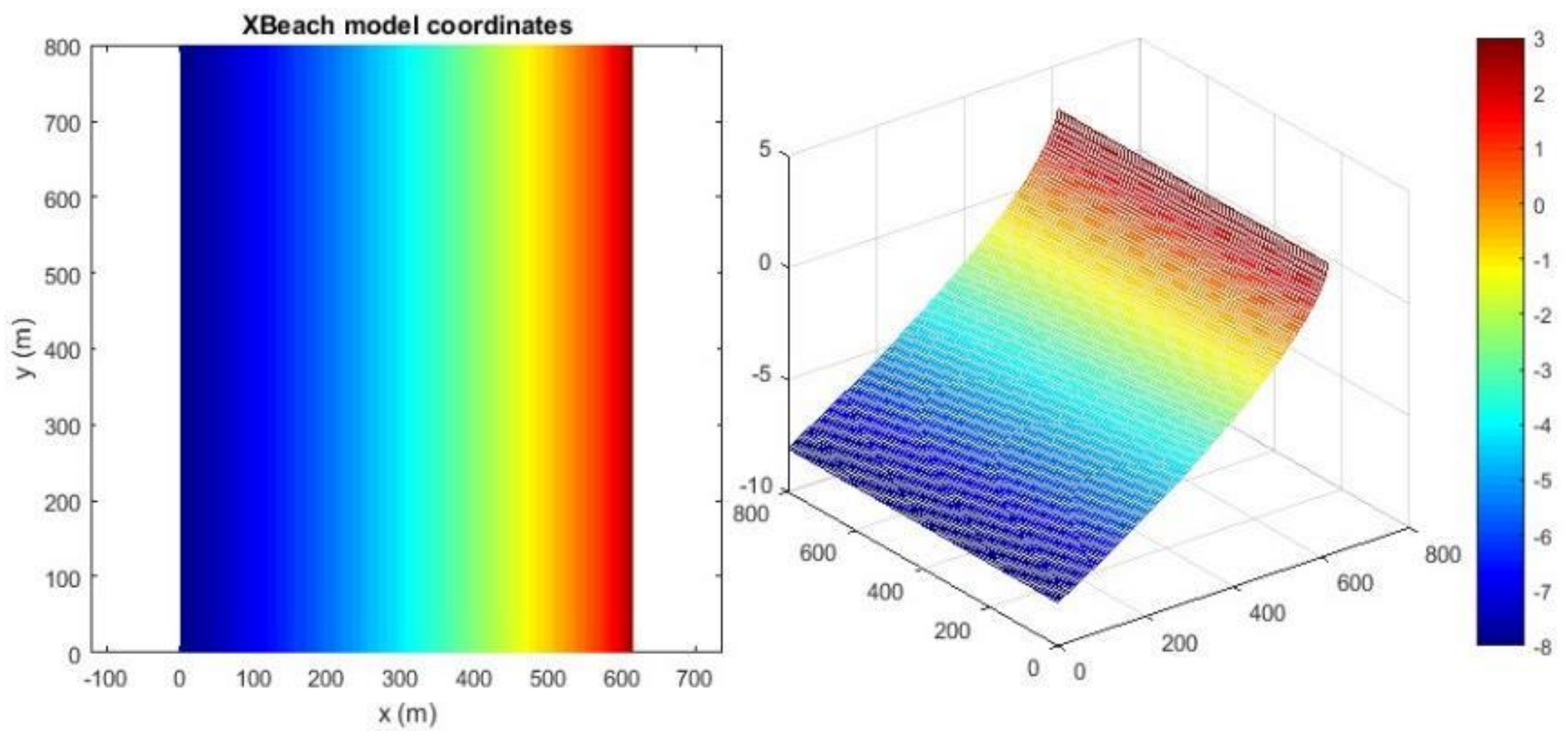

Figura 1. Malla de trabajo. Fuente: elaboración propia. 
Tecnología y

Ciencias $₫$ Agua
2022, Instituto Mexicano de Tecnología del Agua

Open Access bajo la licencia CC BY-NC-SA 4.0

(https://creativecommons.org/licenses/by-nc-sa/4.0/)

Los rompeolas se modelaron tanto dentro como fuera de la zona de rotura. Para el análisis se seleccionaron como alturas de ola significativas los valores de $0.5,1.5$ y $2.5 \mathrm{~m}$, con periodos de 5.5 y $6.5 \mathrm{~s}$, según los datos presentados en el Global Wave Statistics para el área geográfica que abarca Cuba, Área 33, como se observa en la Tabla 1. Se considera la incidencia tanto normal como oblicua del oleaje en la costa.

Tabla 1. Altura de ola y periodos estudiados. Fuente: Global Wave Statistic, Área 33.

\begin{tabular}{|c|c|c|c|c|c|c|c|c|}
\hline $\begin{array}{c}\text { Hs } \\
(\mathbf{m})\end{array}$ & & & & & & & & \\
\hline 8.5 & & & & 1 & 1 & & & \\
\hline 7.5 & & & 1 & 1 & 1 & 1 & & \\
\hline 6.5 & & 1 & 2 & 3 & 2 & 1 & & \\
\hline 5.5 & & 1 & 5 & 6 & 5 & 2 & 1 & \\
\hline 4.5 & & 4 & 12 & 15 & 10 & 4 & 2 & \\
\hline 3.5 & 2 & 13 & 31 & 32 & 49 & 7 & 2 & 1 \\
\hline 2.5 & 6 & 37 & 70 & 59 & 29 & 10 & 3 & 1 \\
\hline 1.5 & 22 & 90 & 49 & 74 & 28 & 7 & 2 & 0 \\
\hline 0.5 & 56 & 96 & 66 & 25 & 6 & 1 & 0 & 0 \\
\hline Tm(s) & 4.5 & 5.5 & 6.5 & 7.5 & 8.5 & 9.5 & 10.5 & 11.5 \\
\hline
\end{tabular}


Tecnología y

Ciencias $\stackrel{\Xi}{\unlhd}$ gua
2022, Instituto Mexicano de Tecnología del Agua

Open Access bajo la licencia CCBY-NC-SA 4.0

(https://creativecommons.org/licenses/by-nc-sa/4.0/)

Las variables hidrodinámicas y morfológicas estudiadas se reflejan en la Tabla 2. Las simulaciones se realizaron variando las variables para conocer los cambios que se generan en la playa, para un total de 440 variantes analizadas.

Tabla 2. Variables hidrodinámicas y morfológicas por estudiar.

\begin{tabular}{|c|c|c|}
\hline Variables & Descripción & Unidades \\
\hline \multicolumn{3}{|c|}{ Hidrodinámicas } \\
\hline Hs & Altura de ola significativa $(0.5,1.5,2.5)$ & $\mathrm{m}$ \\
\hline$T m$ & Periodo medio del oleaje $(5.5,6.5)$ & $\mathrm{s}$ \\
\hline$\theta$ & Incidencia del oleaje $(90,315)$ & $\circ$ \\
\hline \multicolumn{3}{|c|}{ Geométricas del rompeolas } \\
\hline$L b$ & Longitud $(100,200,300)$ & $\mathrm{m}$ \\
\hline$W b$ & Ancho de la cresta $(10,20)$ & $\mathrm{m}$ \\
\hline$S b$ & Sumergencia $(-0.00,-0.50,-1.00)$ & $\mathrm{m}$ \\
\hline$X b$ & $\begin{array}{l}\text { Distancia a la costa }(30,60,90,120,150, \\
180,210,240,270,300)\end{array}$ & $\mathrm{m}$ \\
\hline \multicolumn{3}{|c|}{ Físicas } \\
\hline$m$ & Pendiente de la playa sumergida (0.025) & - \\
\hline$D_{50}$ & Diámetro medio del sedimento $(0.26)$ & $\mathrm{mm}$ \\
\hline$\omega$ & Velocidad de caída del sedimento (4.49) & $\mathrm{cm} / \mathrm{s}$ \\
\hline
\end{tabular}


2022, Instituto Mexicano de Tecnología del Agua

Tecnología y

Open Access bajo la licencia CCBY-NC-SA 4.0

(https://creativecommons.org/licenses/by-nc-sa/4.0/)

$\gamma S$

Peso específico del sedimento (2.716)

$\mathrm{kg} / \mathrm{cm}^{3}$

\section{Resultados}

\section{Efecto de la longitud del rompeolas sumergido (Lb)}

Se presentan los resultados más relevantes obtenidos de la modelación de las variables hidrodinámicas, geométricas del rompeolas y físicas.

En la Figura 2 se puede ver, de izquierda a derecha, la representación de las simulaciones referentes a rompeolas de longitudes de 100,200 y 300 m, respectivamente, con ancho de cresta de $10 \mathrm{~m}$ y sumergencia $-0.5 \mathrm{~m}$, ubicados a $60 \mathrm{~m}$ de la línea de costa. Se definieron los perfiles donde existe mayor interés de análisis que son:

- Perfil 41: perfil que pasa por el centro del rompeolas en todas las variantes; se denomina perfil con la presencia de rompeolas.

- Perfil 16: perfil que pasa por una zona alejada del rompeolas y de la frontera de la malla de trabajo; se denomina perfil sin la presencia de rompeolas. 
Tecnología y

Ciencias $\frac{\approx}{\square}$ gua
2022, Instituto Mexicano de Tecnología del Agua

Open Access bajo la licencia CCBY-NC-SA 4.0

(https://creativecommons.org/licenses/by-nc-sa/4.0/)

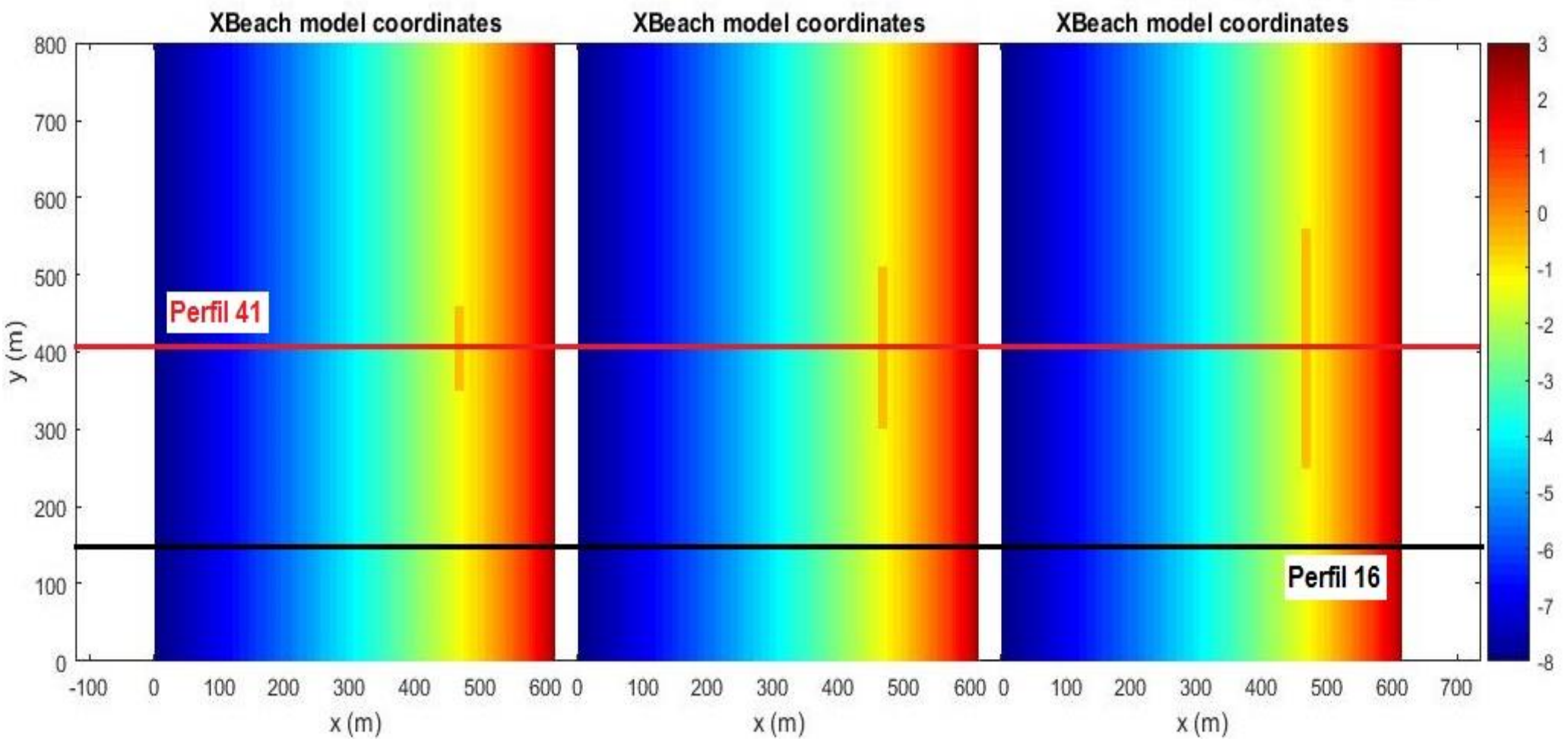

Figura 2. Representación de la malla de trabajo con los rompeolas ubicados a $60 \mathrm{~m}$ y oleaje incidiendo perpendicular a la costa.

La influencia que ejerce el rompeolas sobre la altura media cuadrática de las olas de gravedad se puede valorar cualitativa y cuantitativamente en la Figura 3 y Tabla 3; se observa cómo después de interactuar con el rompeolas sus valores disminuyen en todas las variantes. También se aprecia que el coeficiente de transmisión, que relaciona las alturas de ola transmitidas e incidentes, presenta valores muy similares en las tres variantes, aunque la longitud del rompeolas varíe. 
Tecnología y

Ciencias $\approx$ Agua
2022, Instituto Mexicano de Tecnología del Agua

Open Access bajo la licencia CC BY-NC-SA 4.0

(https://creativecommons.org/licenses/by-nc-sa/4.0/)

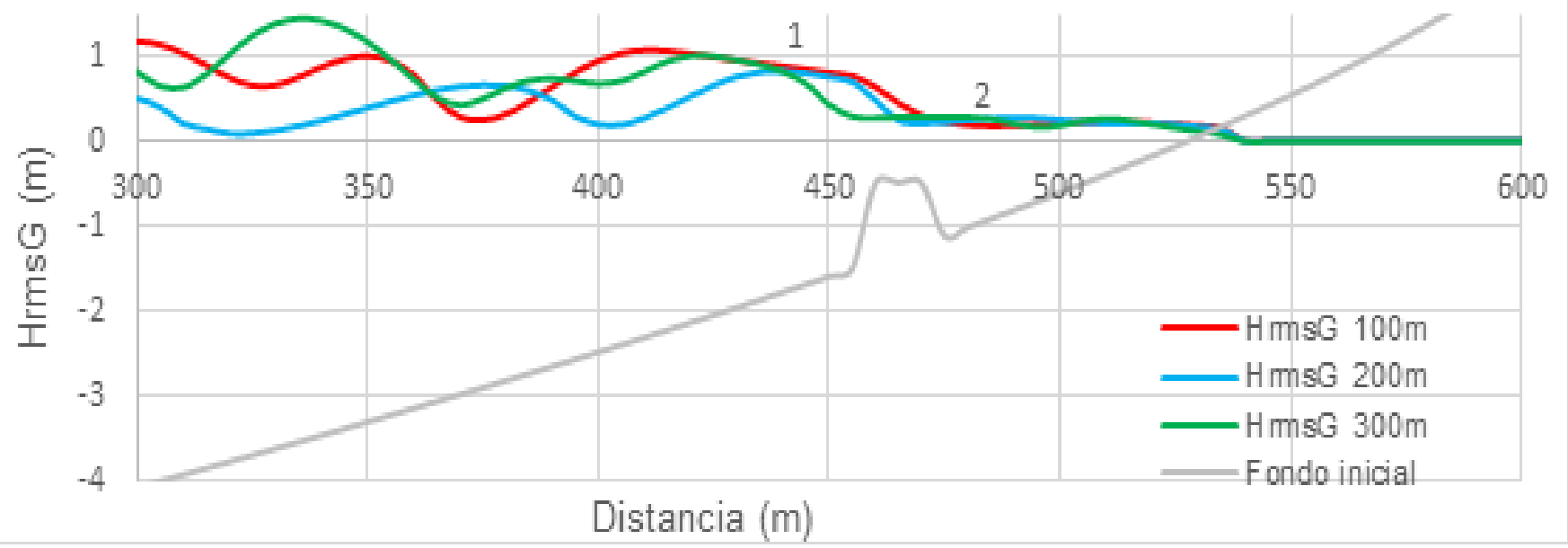

Figura 3. Representación de la altura media cuadrática de las olas de gravedad para los rompeolas de 100, 200 y 300 m de longitud ubicados a $60 \mathrm{~m}$ de la costa. Fuente: elaboración propia.

Tabla 3. Análisis de la transmisión en función de la longitud del rompeolas. Fuente: elaboración propia.

\begin{tabular}{|c|c|c|c|c|}
\hline \multirow{2}{*}{ Variantes } & Longitud & \multicolumn{2}{|c|}{ HrmsG (m) } & \multirow{2}{*}{ Kt } \\
\cline { 3 - 4 } & $\mathbf{( m )}$ & Punto 1 & Punto 2 & \\
\hline 2 & 100 & 0.7826 & 0.2466 & 0.32 \\
\hline 122 & 200 & 0.7140 & 0.2288 & 0.32 \\
\hline 212 & 300 & 0.7801 & 0.2397 & 0.31 \\
\hline
\end{tabular}

Nota: los puntos 1 y 2 están ubicados a $5 \mathrm{~m}$ hacia el mar y hacia la costa de la cresta del rompeolas, respectivamente. 
La Tabla 4 muestra la altura media cuadrática de las olas de gravedad en el perfil 16 sin la presencia de rompeolas, y en el perfil 41 con la presencia de rompeolas; se puede constatar la efectividad del rompeolas al atenuar la energía del oleaje incidente y el porcentaje de disipación que garantiza.

Tabla 4. Altura de ola media cuadrática de las olas de gravedad en el perfil 16 y en el perfil 41. Fuente: elaboración propia.

\begin{tabular}{|c|c|c|c|c|}
\hline \multirow{2}{*}{ Variantes } & \multirow{2}{*}{$\begin{array}{c}\text { Longitud } \\
\mathbf{( m )}\end{array}$} & $\begin{array}{c}|c| \\
\text { Punto 2 } \\
\text { Perfil 16 }\end{array}$ & $\begin{array}{c}\text { Punto 2 } \\
\text { Perfil 41 }\end{array}$ & (\%) \\
\cline { 3 - 4 } & 100 & 0.6428 & 0.2466 & 61.63 \\
\hline 2 & 200 & 0.5437 & 0.2288 & 57.91 \\
\hline 212 & 300 & 0.5168 & 0.2397 & 53.61 \\
\hline
\end{tabular}

Al interactuar con el rompeolas, la velocidad que alcanza el flujo aumenta producto de la fuerte turbulencia que se genera, siendo mayor para el rompeolas que presenta $100 \mathrm{~m}$ de longitud (Figura 4). 
Tecnología y

Ciencias $\approx$ Agua
2022, Instituto Mexicano de Tecnología del Agua

Open Access bajo la licencia CC BY-NC-SA 4.0

(https://creativecommons.org/licenses/by-nc-sa/4.0/)

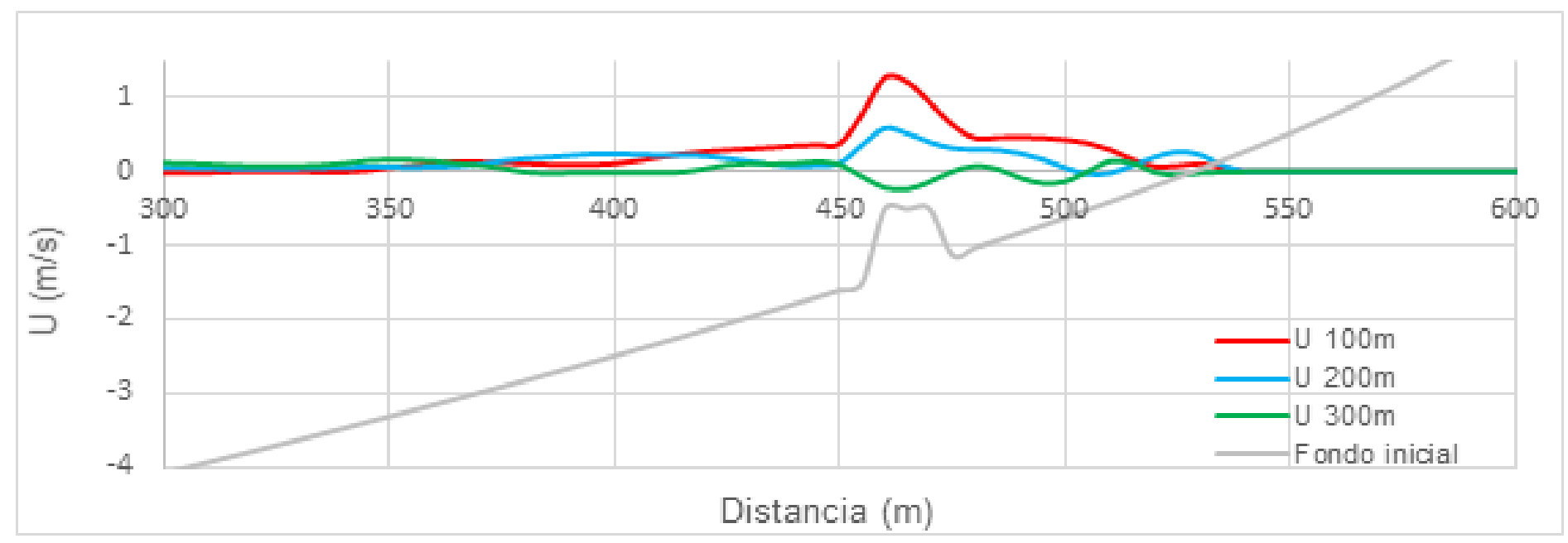

Figura 4. Velocidades del flujo para el rompeolas ubicado a $60 \mathrm{~m}$ de la línea de costa con longitudes de 100, 200 y 300 m.

Los patrones de flujo se muestran en la Figura 5, los cuales se asemejan al patrón erosivo de dos celdas descrito por Ranasinghe et al. (2010), donde la línea roja indica la posición inicial de la costa. Aunque el comportamiento de las corrientes y, por tanto, la forma en que cambia el fondo es similar en las tres variantes, la zona de influencia aumenta mientras mayor es la longitud del rompeolas. 
2022, Instituto Mexicano de Tecnología del Agua

Ciencias $₫$ Agua

Open Access bajo la licencia CC BY-NC-SA 4.0

(https://creativecommons.org/licenses/by-nc-sa/4.0/)
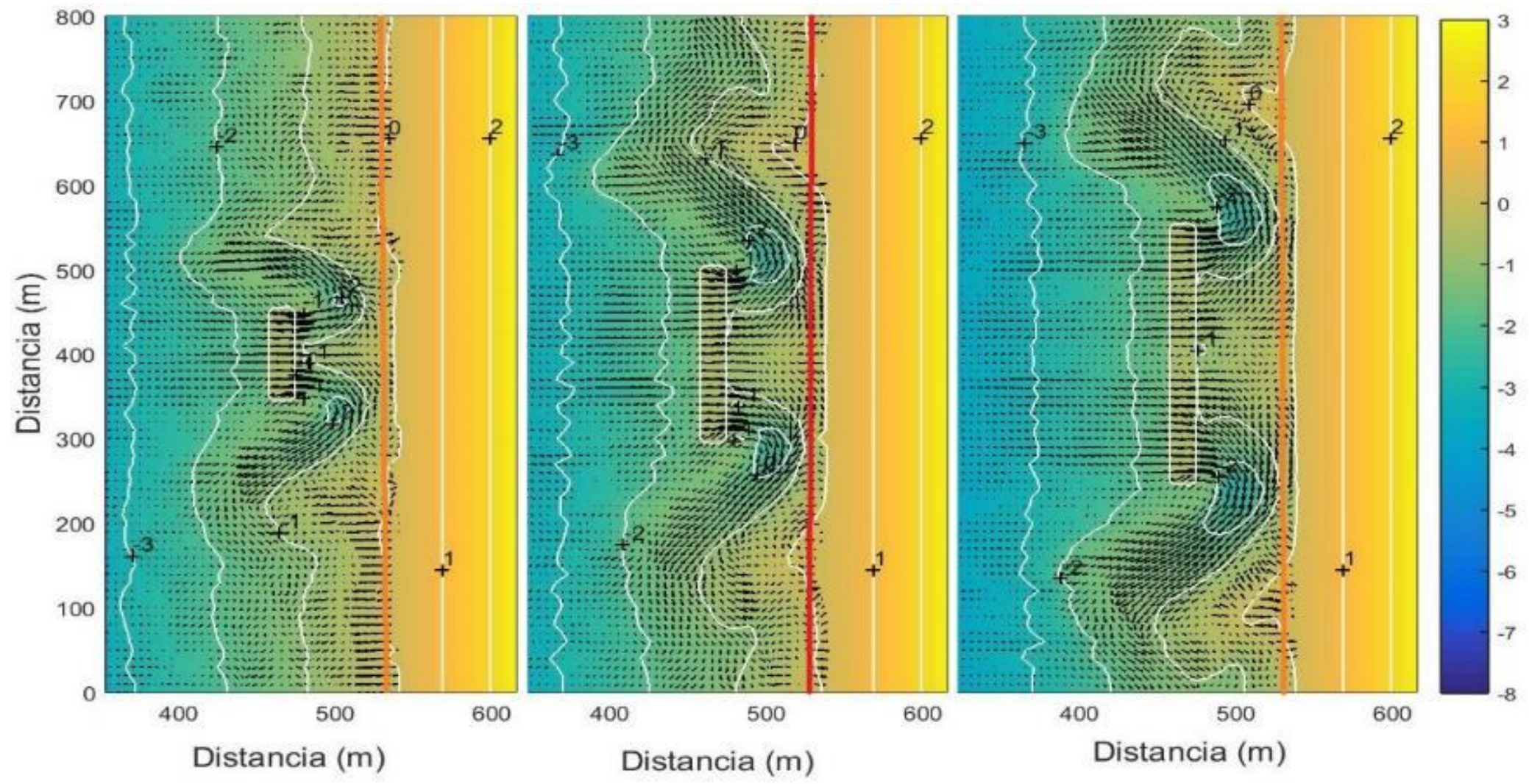

Figura 5. Representación de los patrones de flujo y la variación del fondo para los rompeolas ubicados a $60 \mathrm{~m}$ de la costa.

La Figura 6 revela cómo aumenta el valor del setup del oleaje después de la interacción con el rompeolas. Comparando el setup alrededor de la línea de costa, se nota cómo esta variable disminuye en las tres variantes analizadas justo al centro de la zona de abrigo, por donde transita el perfil 41. La Tabla 5 muestra la sobreelevación en el perfil 16 sin la presencia de rompeolas y en el perfil 41 con la presencia de rompeolas, tanto para el punto 1 situado $5 \mathrm{~m}$ después de sobrepasada la cresta del rompeolas, como para el punto 2 situado en la línea de costa. 
Tecnología y

Ciencias $₫$ Agua
2022, Instituto Mexicano de Tecnología del Agua

Open Access bajo la licencia CCBY-NC-SA 4.0

(https://creativecommons.org/licenses/by-nc-sa/4.0/)

En ella puede observarse cómo en el perfil 16, los valores del setup en el punto 2 al llegar a la costa son mayores que para la variante con rompeolas, lo que se aprecia claramente en la Figura 6, donde la línea roja representa la posición inicial de la costa.
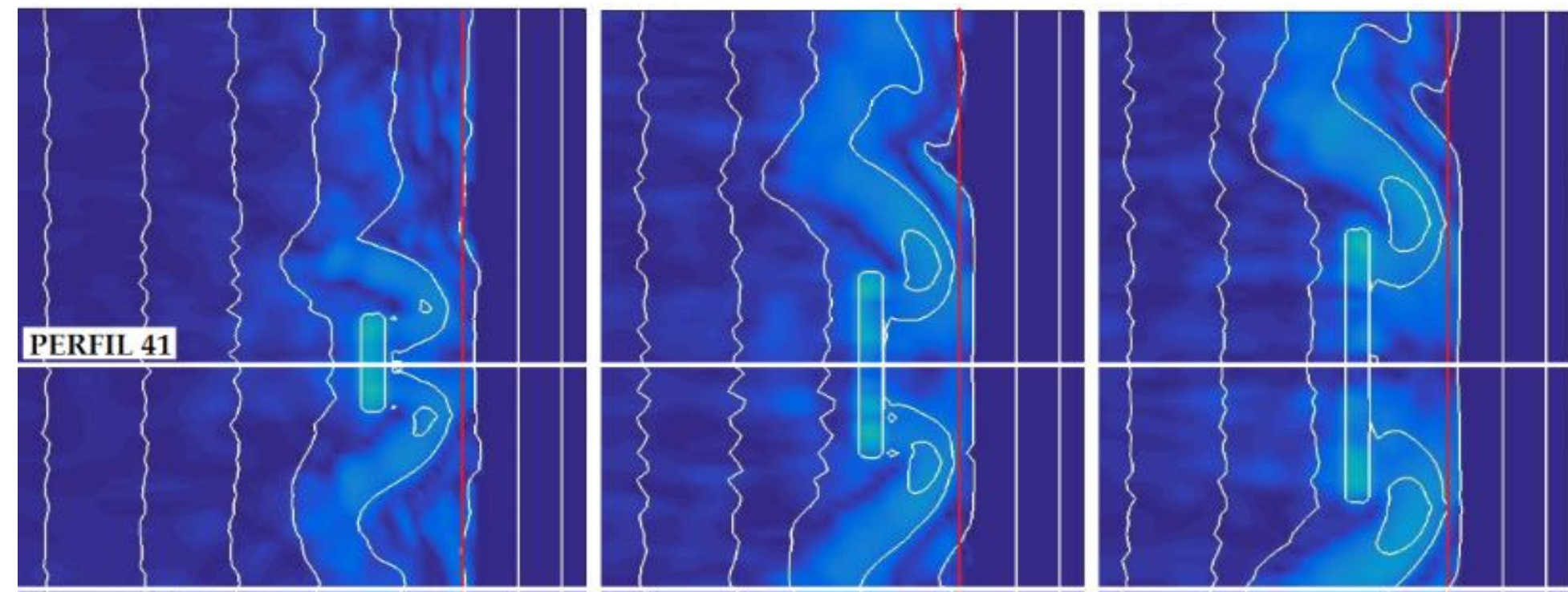

PERFIL 16

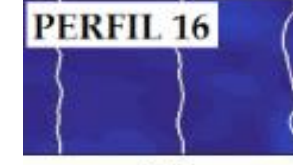

300

400
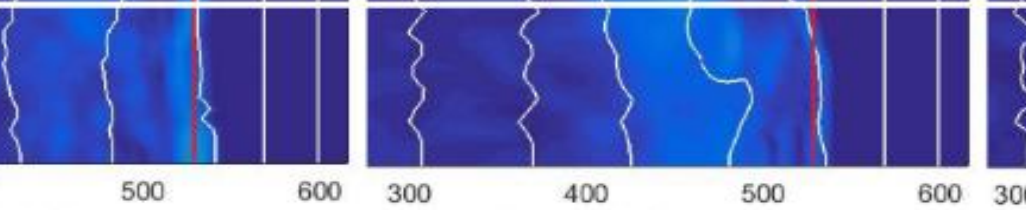

Distancia $(\mathrm{m})$

Distancia $(\mathrm{m})$

600300

500

600300

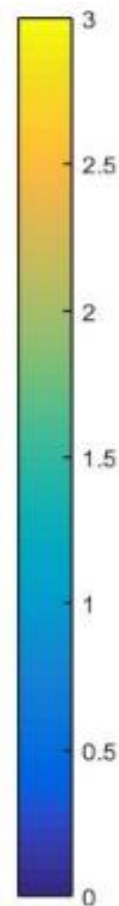

600

Figura 6. Representación del setup Zs para los rompeolas ubicados a $60 \mathrm{~m}$ de la costa con longitudes de 100, 200 y $300 \mathrm{~m}$.

Tabla 5. Sobreelevación del nivel del mar en el perfil 16 y en el perfil 41. Fuente: elaboración propia.

\begin{tabular}{|l|l|l|l|}
\hline Variantes & Perfil 16 & Perfil 41 \\
\hline
\end{tabular}


Tecnología y

Ciencias $₫$ Agua
2022, Instituto Mexicano de Tecnología del Agua

Open Access bajo la licencia CC BY-NC-SA 4.0

(https://creativecommons.org/licenses/by-nc-sa/4.0/)

\begin{tabular}{|c|c|c|c|c|c|}
\hline & $\begin{array}{c}\text { Longitud } \\
\mathbf{( m )}\end{array}$ & Punto 1 & Punto 2 & Punto 1 & Punto 2 \\
\hline 2 & 100 & 0.1133 & 0.2283 & 0.1101 & 0.1709 \\
\hline 122 & 200 & 0.1447 & 0.1899 & 0.1271 & 0.1803 \\
\hline 212 & 300 & 0.0413 & 0.2430 & 0.1049 & 0.1484 \\
\hline
\end{tabular}

La línea roja de la Figura 7 muestra la posición de la costa antes de la ubicación del rompeolas, atestiguando los cambios morfológicos que sufre el fondo y el proceso erosivo ocurrido. Las corrientes generadas por la presencia del rompeolas transportan los sedimentos que se encuentran en el área de abrigo hacia mar afuera, creando en sus extremos zonas de mayores profundidades y el retraimiento de la línea costera en todo el frente de playa. La formación de socavaciones en los extremos del área de abrigo de los rompeolas puede afectar su estabilidad provocando un fallo abrupto y coincide con la investigación desarrollada en modelos físicos por Papadopoulos (2012). 
Tecnología y

Ciencias 콤
2022, Instituto Mexicano de Tecnología del Agua

Open Access bajo la licencia CC BY-NC-SA 4.0

(https://creativecommons.org/licenses/by-nc-sa/4.0/)

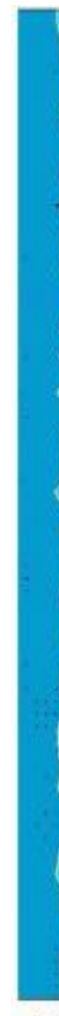

300

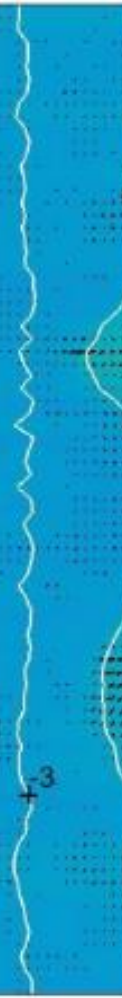

400

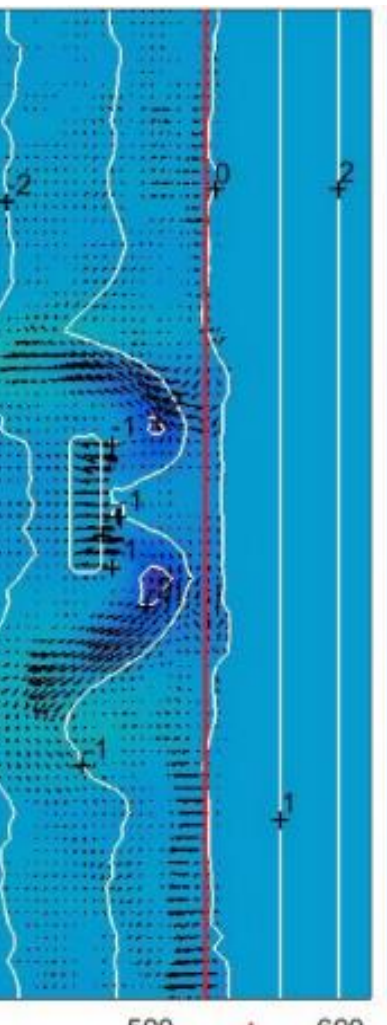

500
300

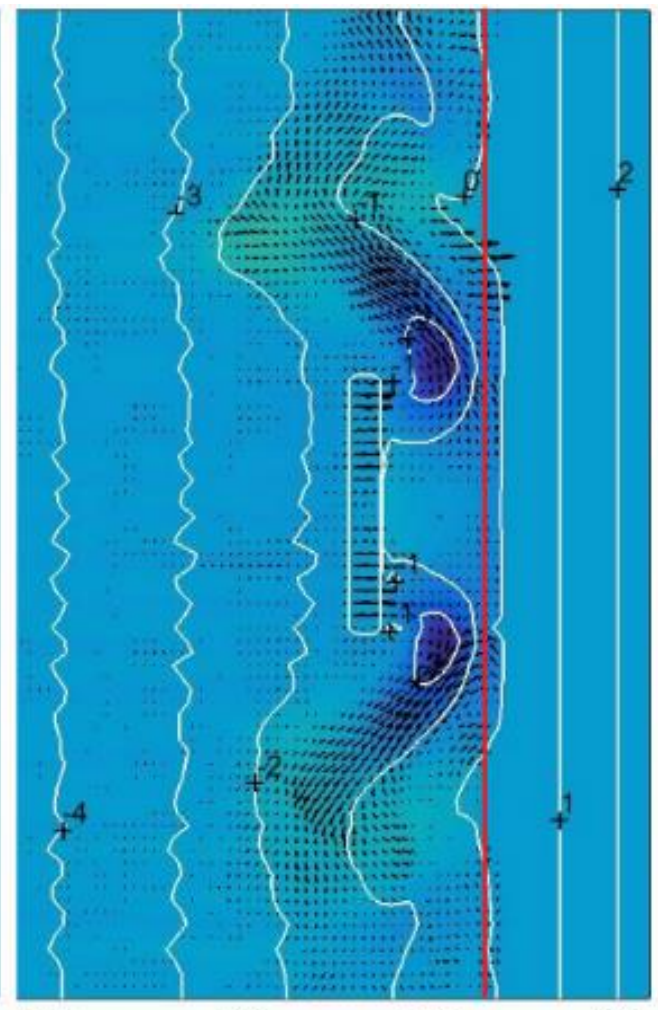

400
500
600300

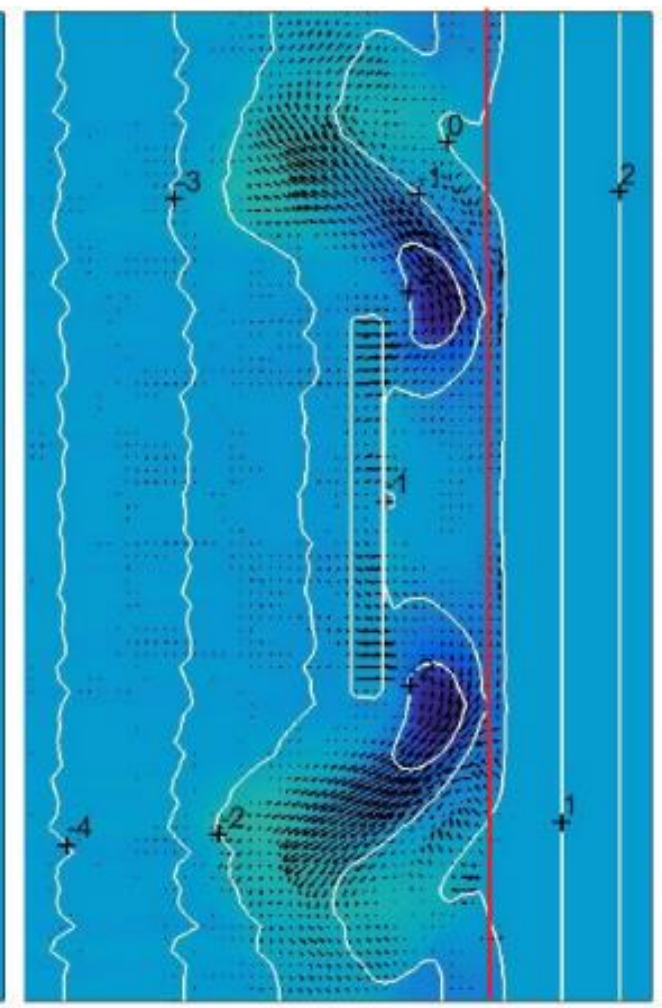

$\operatorname{Distancia}(\mathrm{m})$

$\operatorname{Distancia}(\mathrm{m})$

500
600
1

$\operatorname{Distancia}(\mathrm{m})$

Figura 7. Representación del transporte de sedimento y la variación del fondo. Fuente: elaboración propia.

El perfil resultante que pasa por el centro del rompeolas para las variantes analizadas muestra la evolución morfológica del fondo marino, donde la línea costera presenta pérdida de sedimentos y retroceso, como se percibe en la Figura 8. Para el rompeolas de $100 \mathrm{~m}$ de longitud, el perfil sufre un mayor proceso erosivo, lo que se asocia con las velocidades que alcanzan las corrientes. 
Tecnología y

\section{Ciencias $₫$ Agua}

2022, Instituto Mexicano de Tecnología del Agua

Open Access bajo la licencia CC BY-NC-SA 4.0

(https://creativecommons.org/licenses/by-nc-sa/4.0/)
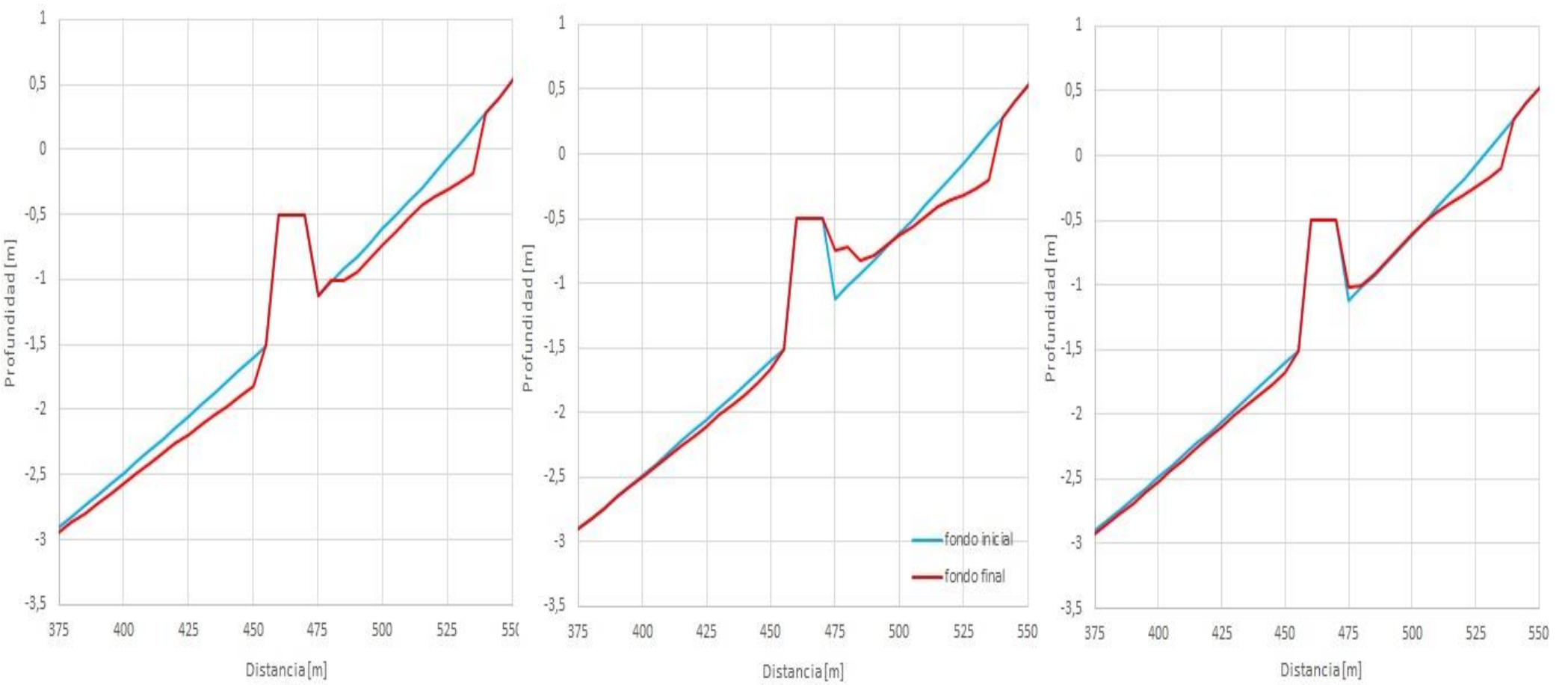

Figura 8. Evolución del fondo marino para rompeolas de $100 \mathrm{~m}$ (izquierda), $200 \mathrm{~m}$ (centro) y $300 \mathrm{~m}$ de longitud (derecha).

\section{Efecto del ancho de la cresta (Wb)}

En la Figura 9 se presentan las simulaciones a rompeolas de 100, 200 y $300 \mathrm{~m}$ de longitud, con ancho de cresta de $20 \mathrm{~m}$ y sumergencia $-0.5 \mathrm{~m}$, ubicados a $60 \mathrm{~m}$ con oleaje incidiendo perpendicular a la costa. La Tabla 6 expone la altura de ola media cuadrática de las olas de gravedad 
Tecnología y

Ciencias $₫$ Agua
2022, Instituto Mexicano de Tecnología del Agua

Open Access bajo la licencia CC BY-NC-SA 4.0

(https://creativecommons.org/licenses/by-nc-sa/4.0/)

obtenidas. Sus valores prueban que el coeficiente de transmisión es menor comparado con las variantes de $10 \mathrm{~m}$ de ancho, siendo el rompeolas más efectivo en la disipación de la altura de ola, lo que coincide con el estudio de Makris y Memos (2007).

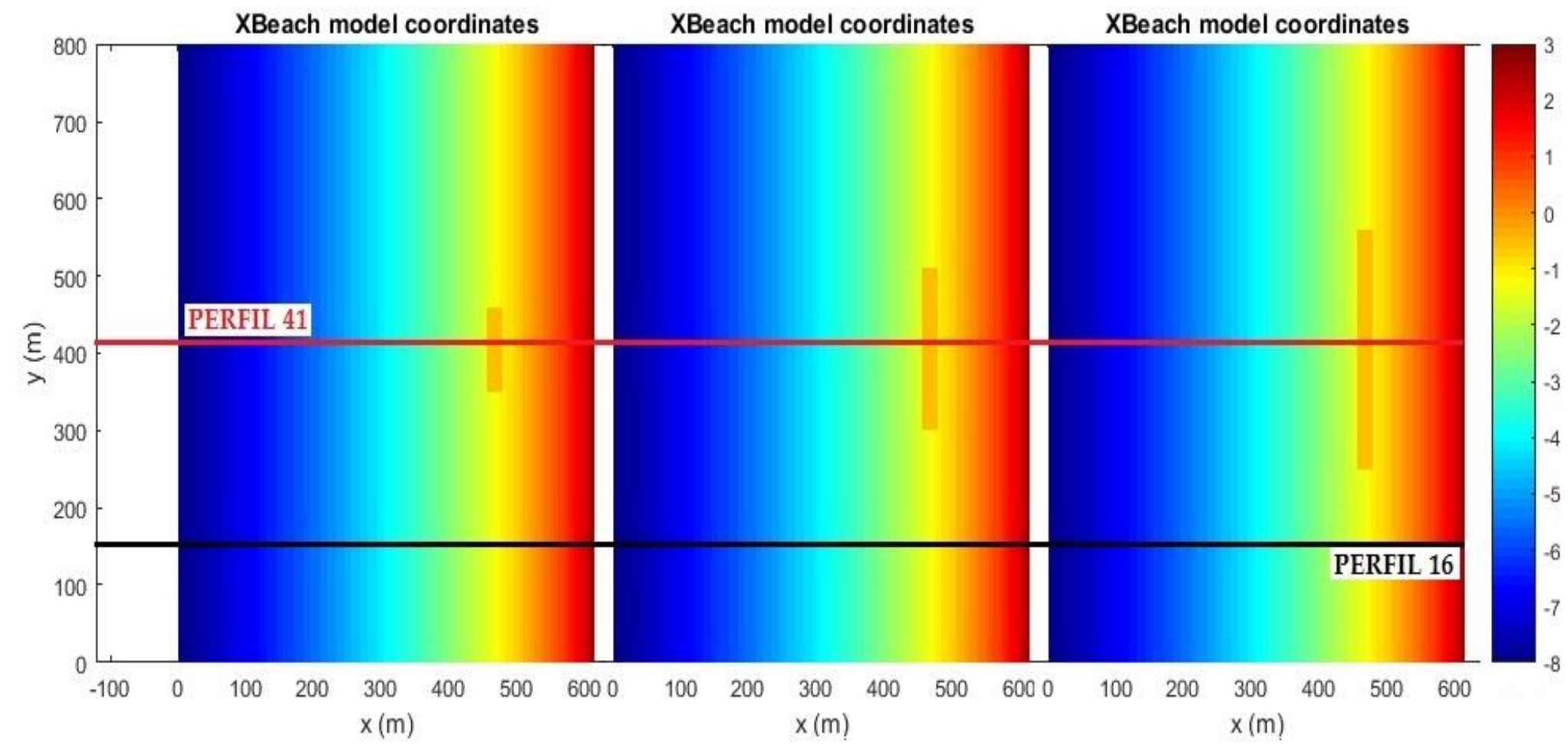

Figura 9. Malla de trabajo con rompeolas de $20 \mathrm{~m}$ de ancho de cresta y longitudes de 100, 200 y 300 m ubicados a 60 m de la costa.

Tabla 6. Análisis de la transmisión en función del ancho de cresta del rompeolas. Fuente: elaboración propia.

\begin{tabular}{|c|c|c|c|c|}
\hline Variantes & & & Hrms (m) & Kt \\
\hline
\end{tabular}


Tecnología y

Ciencias $\approx$ Agua
2022, Instituto Mexicano de Tecnología del Agua

Open Access bajo la licencia CC BY-NC-SA 4.0

(https://creativecommons.org/licenses/by-nc-sa/4.0/)

\begin{tabular}{|c|c|c|c|c|c|}
\hline & $\begin{array}{l}\text { Longitud } \\
\text { (m) }\end{array}$ & $\begin{array}{c}\text { Ancho del } \\
\text { rompeolas } \\
\text { (m) }\end{array}$ & Punto 1 & Punto 2 & \\
\hline 2 & \multirow{2}{*}{100} & 10 & 0.7826 & 0.2466 & 0.32 \\
\hline 92 & & 20 & 0.8183 & 0.2197 & 0.27 \\
\hline 122 & \multirow{2}{*}{200} & 10 & 0.7140 & 0.2288 & 0.32 \\
\hline 392 & & 20 & 0.7867 & 0.2172 & 0.28 \\
\hline 212 & \multirow{2}{*}{300} & 10 & 0.7801 & 0.2397 & 0.31 \\
\hline 402 & & 20 & 0.8055 & 0.2177 & 0.27 \\
\hline
\end{tabular}

Nota: los puntos 1 y 2 están ubicados a $5 \mathrm{~m}$ hacia el mar y hacia la costa de la cresta del rompeolas, respectivamente.

La Figura 10 refleja la relación del parámetro adimensional Wb/Hi y el coeficiente de transmisión $K t$, para los rompeolas de 100 m, 200 m y $300 \mathrm{~m}$ de longitud ubicados en las diferentes posiciones estudiadas. Como se observa, los mayores valores del coeficiente de transmisión corresponden a los rompeolas con ancho de cresta de $10 \mathrm{~m}$, mientras disminuyen significativamente para los rompeolas que presentan $20 \mathrm{~m}$ de ancho. 
Tecnología y

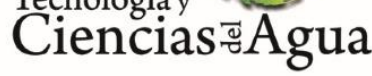

2022, Instituto Mexicano de Tecnología del Agua

Open Access bajo la licencia CC BY-NC-SA 4.0

(https://creativecommons.org/licenses/by-nc-sa/4.0/)

0.60
0.50
0.40
$\approx$
0.30
0.20
0.10
0.00

0

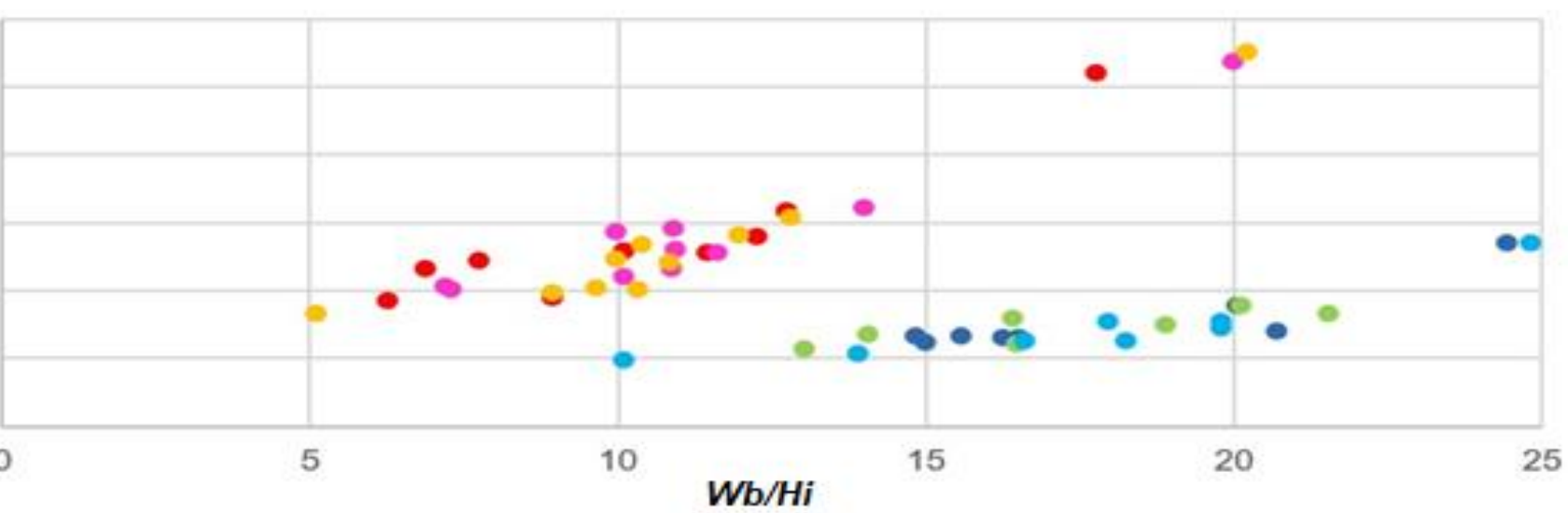

- Longitud $100 \mathrm{~m}$ Ancho $10 \mathrm{~m}$ - Longitud $200 \mathrm{~m}$ Ancho $10 \mathrm{~m}$ - Longitud $300 \mathrm{~m}$ Ancho $10 \mathrm{~m}$

- Longitud $100 \mathrm{~m}$ Ancho $20 \mathrm{~m}$ • Longitud $200 \mathrm{~m}$ Ancho $20 \mathrm{~m}$ - Longitud $300 \mathrm{~m}$ Ancho $20 \mathrm{~m}$

Figura 10. Relación entre el parámetro adimensional $(W b / H i)$ y el coeficiente de transmisión $K t$, para rompeolas de $10 \mathrm{~m}$ y $20 \mathrm{~m}$ de ancho.

En la Tabla 7 se puede observar la velocidad del flujo que alcanza el oleaje en su interacción con el rompeolas. Al comparar las variantes con ancho de 10 y 20 m se aprecia cómo es mayor para esta última debido a la turbulencia que se genera por el aumento de la rotura del oleaje.

Tabla 7. Velocidades del flujo al interactuar (punto 1) y después de interactuar con el rompeolas (punto 2).

\begin{tabular}{|c|c|c|c|c|}
\hline Variantes & Longitud & \multirow{2}{|c|}{$\begin{array}{c}\text { Ancho del } \\
\text { rompeolas }\end{array}$} & \multicolumn{2}{|c|}{ Velocidad (m/s) } \\
\cline { 4 - 5 } & $(\mathbf{m})$ & Punto 1 & Punto 2 \\
& & 10 & 1.2546 & 0.4467 \\
\hline
\end{tabular}


Tecnología y

Ciencias $₫$ Agua
2022, Instituto Mexicano de Tecnología del Agua

Open Access bajo la licencia CC BY-NC-SA 4.0

(https://creativecommons.org/licenses/by-nc-sa/4.0/)

\begin{tabular}{|c|c|c|c|c|}
\hline 92 & 100 & 20 & 1.6576 & 0.5511 \\
\hline 122 & \multirow{3}{*}{200} & 10 & 0.5803 & 0.3137 \\
\cline { 3 - 5 } & & 20 & 0.6180 & 0.4264 \\
\hline 292 & \multirow{2}{*}{300} & 10 & 0.2050 & 0.1299 \\
\cline { 4 - 5 } & & 20 & 0.4631 & 0.1204 \\
\hline 4
\end{tabular}

En cuanto a los patrones de flujo y circulación de las corrientes, para las variantes analizadas se presentan de naturaleza erosiva. En la Figura 11 se observan estos patrones, con el retroceso de la línea costera tanto para el rompeolas de $10 \mathrm{~m}$ de ancho de cresta como para el rompeolas de $20 \mathrm{~m}$ de ancho; para este último es más pronunciado, donde la línea de color rojo representa la posición inicial de la costa. 
2022, Instituto Mexicano de Tecnología del Agua

Ciencias $₫$ Agua

Open Access bajo la licencia CC BY-NC-SA 4.0

(https://creativecommons.org/licenses/by-nc-sa/4.0/)
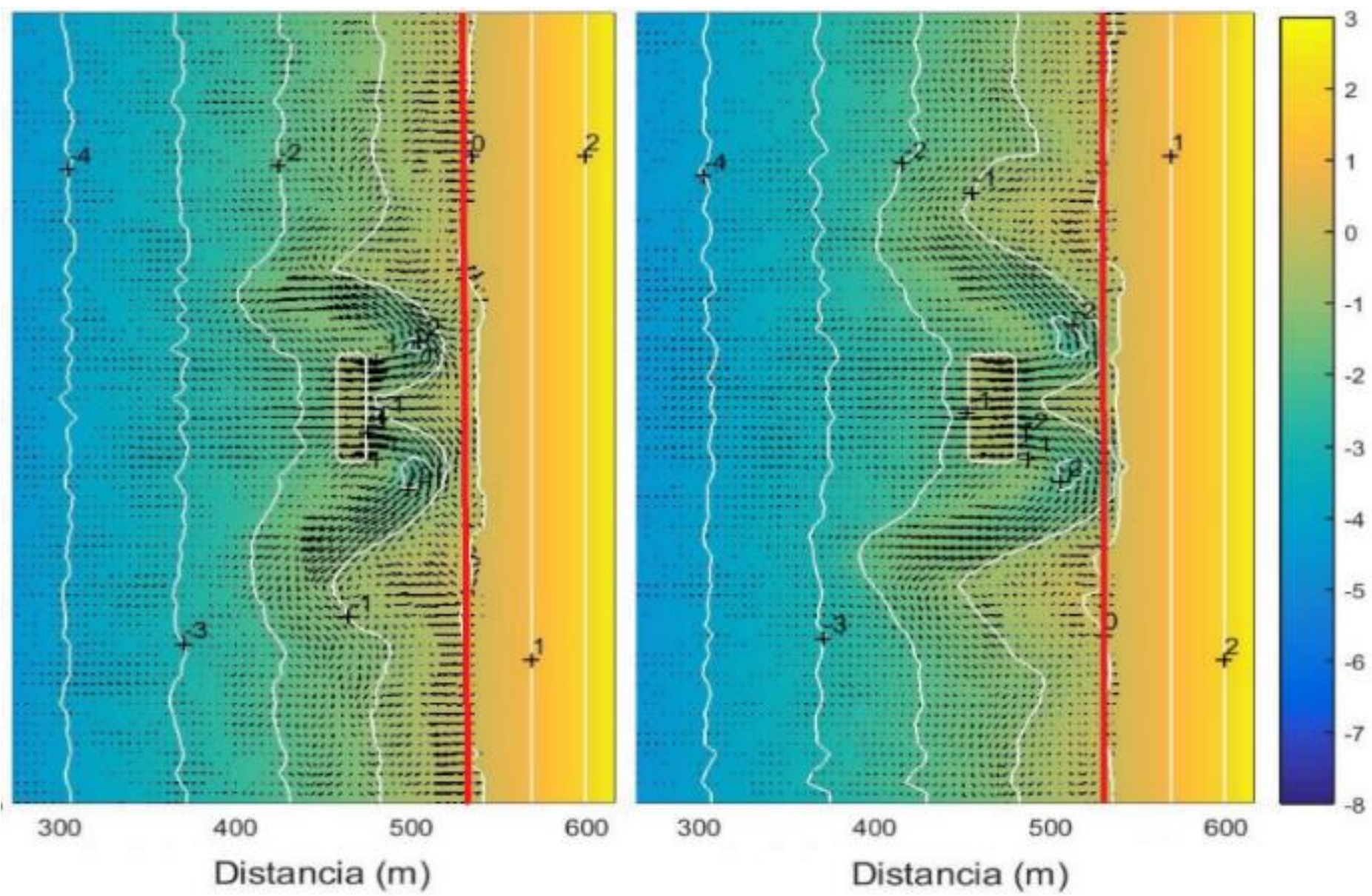

Figura 11. Patrones de circulación de las corrientes para el rompeolas de $100 \mathrm{~m}$ de longitud ubicado a $60 \mathrm{~m}$ de la costa. Izquierda: variante con 10 m de ancho; derecha: variante con 20 m de ancho.

La Tabla 8 muestra la sobreelevación del oleaje en el perfil 16 sin la presencia de rompeolas y en el perfil 41 con la presencia de rompeolas tanto para el punto 1 ubicado a $5 \mathrm{~m}$ de la cresta del rompeolas como en el punto 2 situado en la línea costera, correspondiente a los rompeolas de $20 \mathrm{~m}$ de ancho. Al comparar los valores con los dados en la Tabla 5 para 
Tecnología y

Ciencias $₫$ Agua
2022, Instituto Mexicano de Tecnología del Agua

Open Access bajo la licencia CC BY-NC-SA 4.0

(https://creativecommons.org/licenses/by-nc-sa/4.0/)

los rompeolas de $10 \mathrm{~m}$ de ancho se observa cómo la sobreelevación del nivel del mar en la línea costera aumenta, lo que se puede apreciar claramente en la Figura 12.

Tabla 8. Sobreelevación del nivel del mar en el perfil 16 y en el perfil 41 para rompeolas de $20 \mathrm{~m}$ de ancho de cresta.

\begin{tabular}{|c|c|c|c|c|c|}
\hline \multirow{2}{*}{ Variantes } & Longitud & \multicolumn{2}{|c|}{ Perfil 16 } & \multicolumn{2}{c|}{ Perfil 41 } \\
\cline { 3 - 6 } & $(\mathbf{m})$ & Punto 1 & Punto 2 & Punto 1 & Punto 2 \\
\hline 92 & 100 & 0.0857 & 0.1899 & 0.1756 & 0.2129 \\
\hline 392 & 200 & 0.1628 & 0.2066 & 0.1429 & 0.1951 \\
\hline 402 & 300 & 0.1244 & 0.2052 & 0.2409 & 0.1676 \\
\hline
\end{tabular}
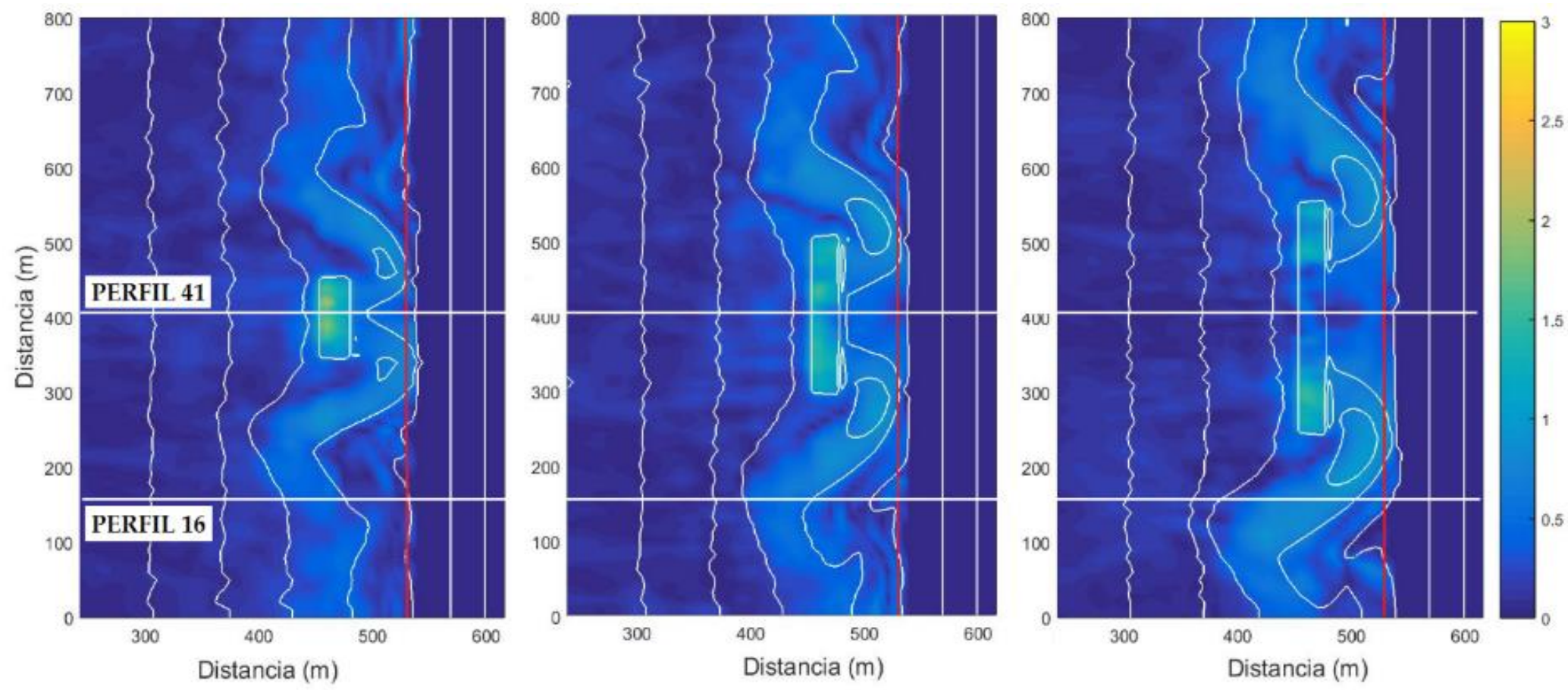
Tecnología y

Ciencias $\stackrel{\Xi}{\unlhd}$ Aua
2022, Instituto Mexicano de Tecnología del Agua

Open Access bajo la licencia CC BY-NC-SA 4.0

(https://creativecommons.org/licenses/by-nc-sa/4.0/)

Figura 12. Setup del oleaje para rompeolas de $20 \mathrm{~m}$ de ancho ubicados a 60 m de la costa con longitudes de 100, 200 y 300 m.

Al observar el comportamiento del perfil 41, que pasa por el centro del rompeolas de $100 \mathrm{~m}$ de longitud, se nota la evolución morfológica del fondo marino, donde la línea costera presenta pérdida de sedimentos y retroceso, como se percibe en la Figura 13. Para el rompeolas con $20 \mathrm{~m}$ de ancho existe una marcada erosión en todo el perfil, que se intensifica en su base debido al aumento de las velocidades del flujo, lo que pudiera provocar el fallo de la estructura.
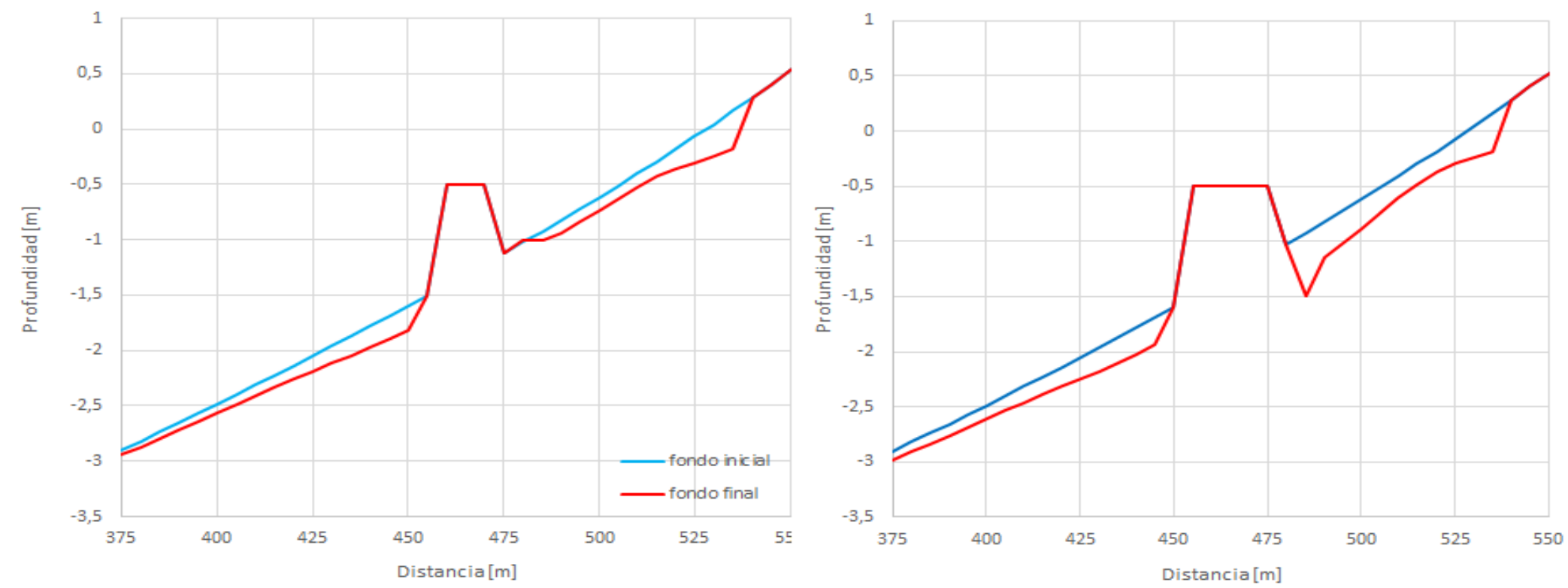

Figura 13. Comportamiento del fondo. Derecha: rompeolas de $10 \mathrm{~m}$ de ancho; izquierda: rompeolas de $20 \mathrm{~m}$ de ancho. 
Tecnología y

Ciencias $₫$ Agua
2022, Instituto Mexicano de Tecnología del Agua

Open Access bajo la licencia CC BY-NC-SA 4.0

(https://creativecommons.org/licenses/by-nc-sa/4.0/)

\section{Efecto de la sumergencia (Sb)}

El efecto de la sumergencia se observa a través del coeficiente de transmisión en la Figura 14, donde para los rompeolas de sumergencia $0.00 \mathrm{~m}$, los valores disminuyen hasta muy próximos a cero mientras que aumentan con el incremento de la sumergencia hasta alcanzar valores de 0.54 para rompeolas con sumergencia de $-1.00 \mathrm{~m}$.

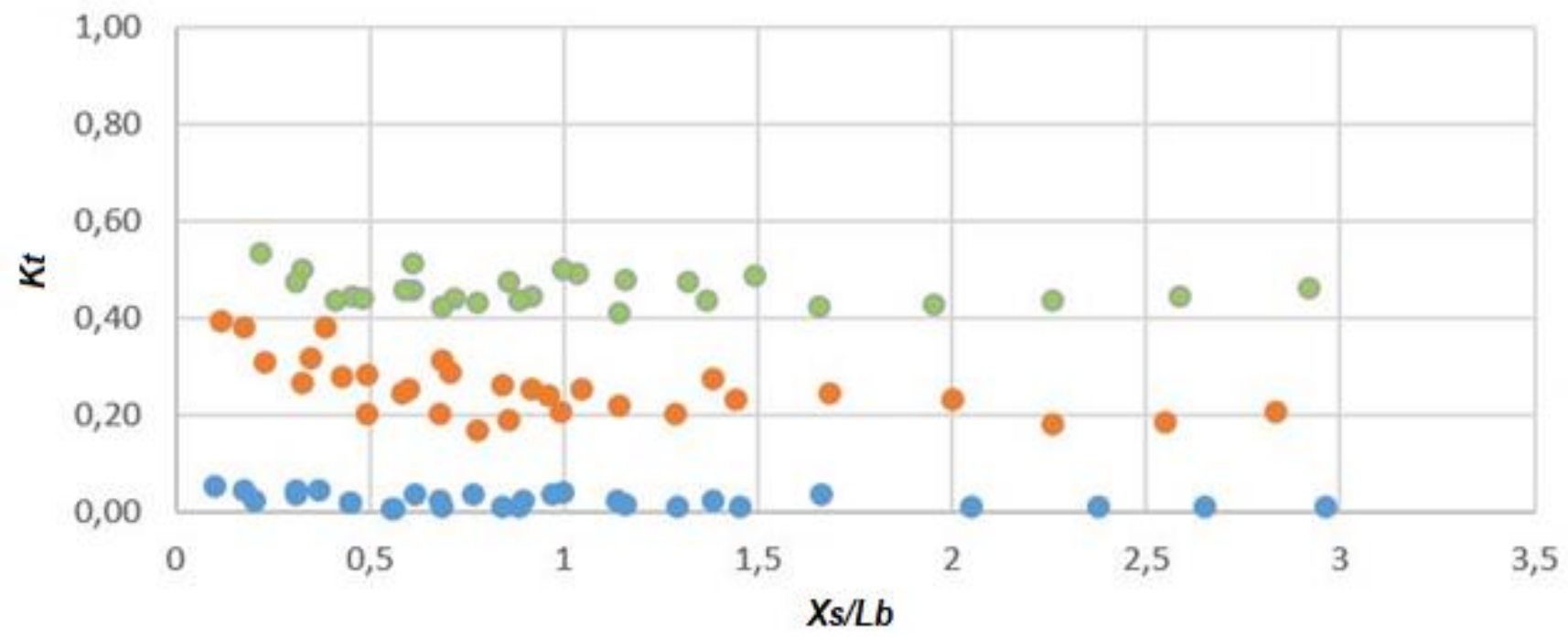

- Sumergencia $0,00 \mathrm{~m}$ • Sumergencia $-0,50 \mathrm{~m}$ e Sumergencia $-1,00 \mathrm{~m}$

Figura 14. Efectos de la sumergencia sobre el coeficiente de transmisión. 
Tecnología y

Ciencias $\cong$ Agua
2022, Instituto Mexicano de Tecnología del Agua

Open Access bajo la licencia CC BY-NC-SA 4.0

(https://creativecommons.org/licenses/by-nc-sa/4.0/)

La Figura 15 refleja el transporte de sedimentos generado por la presencia del rompeolas ubicado a $120 \mathrm{~m}$ de la costa con sumergencia de $0.00 \mathrm{~m},-0.50 \mathrm{~m}$ y $-1.00 \mathrm{~m}$, donde su efecto sobre la playa disminuye a medida que aumenta la sumergencia, lo que fue señalado por (Calabrese, Vicinanza, \& Buccino, 2008) y verificado por Ranasinghe et al. (2010).

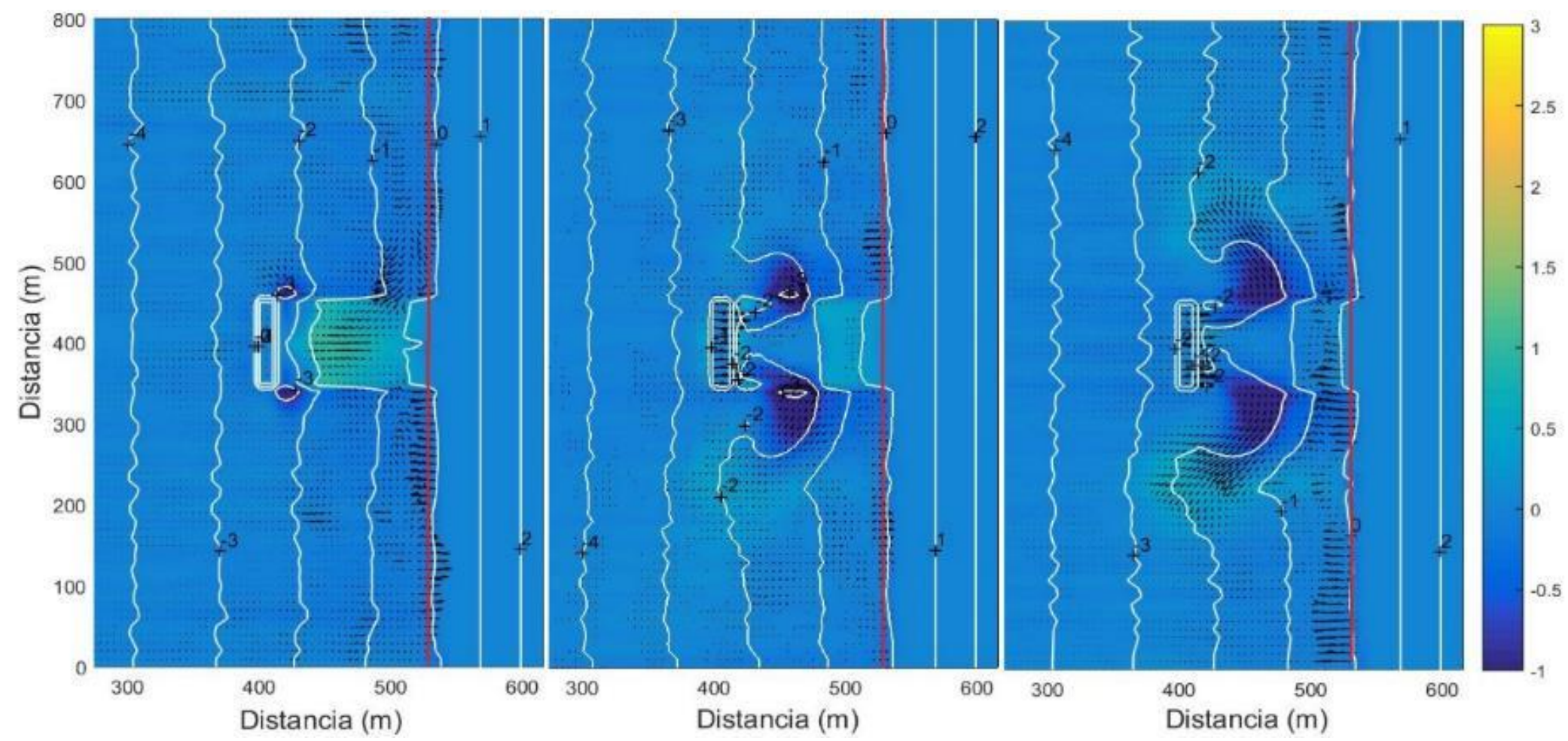

Figura 15. Transporte de sedimentos. Izquierda: sumergencia de 0.00 m; centro: sumergencia de $-0.50 \mathrm{~m}$; derecha: sumergencia de $-1.00 \mathrm{~m}$.

\section{Efecto de la oblicuidad del oleaje $(\theta)$}


Las modelaciones realizadas bajo la influencia oblicua del oleaje experimentan un comportamiento similar al obtenido bajo el oleaje actuando perpendicular a la costa, lo que coincide con las investigaciones realizadas por Vanlishout (2008) y con los planteamientos de Ranasinghe et al. (2010). La Tabla 9 y Tabla 10 muestran los coeficientes de transmisión y la sobreelevación del oleaje para rompeolas ubicados a 60 m de la costa con 100, 200 y 300 m de longitud bajo el accionar oblicuo del oleaje, que se pueden comparar con la Tabla 3 y Tabla 6, donde el oleaje actúa perpendicular a la costa.

Tabla 9. Análisis de la transmisión en función de la incidencia del oleaje. Rompeolas de $10 \mathrm{~m}$ de ancho de corona y sumergencia de -0-50 $\mathrm{m}$.

\begin{tabular}{|c|c|c|c|c|}
\hline \multirow{2}{*}{ Variantes } & \multirow{2}{*}{$\begin{array}{c}\text { Longitud } \\
\text { (m) }\end{array}$} & \multicolumn{2}{|c|}{ HrmsG (m) } & \multirow{2}{*}{ Kt } \\
\cline { 3 - 4 } & & Punto 1 & Punto 2 & \\
\hline 302 & 100 & 0.7864 & 0.2399 & 0.31 \\
\hline 332 & 200 & 0.5452 & 0.1680 & 0.31 \\
\hline 362 & 300 & 0.7879 & 0.2466 & 0.31 \\
\hline
\end{tabular}

Tabla 10. Valores de la sobrelevación del nivel del mar. Rompeolas de $10 \mathrm{~m}$ de ancho de corona y sumergencia de $-0.50 \mathrm{~m}$. 


\begin{tabular}{|c|c|c|c|c|c|}
\hline \multirow{2}{*}{ Variantes } & $\begin{array}{c}\text { Longitud } \\
(\mathbf{m})\end{array}$ & \multicolumn{2}{|c|}{ Perfil 16 } & \multicolumn{2}{c|}{ Perfil 41 } \\
\cline { 3 - 6 } & & Punto 1 & Punto 2 & Punto 1 & Punto 2 \\
\hline 302 & 100 & 0.1241 & 0.2329 & 0.1038 & 0.1899 \\
\hline 332 & 200 & 0.1130 & 0.1923 & 0.1219 & 0.1733 \\
\hline 362 & 300 & 0.0532 & 0.2312 & 0.1148 & 0.1609 \\
\hline
\end{tabular}

Los patrones de flujo y circulación de las corrientes presentan un comportamiento similar al observado para el oleaje actuando normal a la costa, con el retroceso de la línea costera para las ubicaciones cercanas, como muestra la Figura 16. La evolución morfológica del fondo marino bajo la incidencia oblicua del oleaje puede observarse en la Figura 17, donde la línea costera presenta un comportamiento muy similar al obtenido bajo el oleaje actuando perpendicular a la costa, con pérdida de sedimentos y retroceso, lo que evidencia que la oblicuidad del oleaje no ejerce influencia significativa en el modo de respuesta de la costa. 
Tecnología y

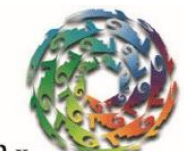

Ciencias
2022, Instituto Mexicano de Tecnología del Agua

Open Access bajo la licencia CC BY-NC-SA 4.0

(https://creativecommons.org/licenses/by-nc-sa/4.0/)
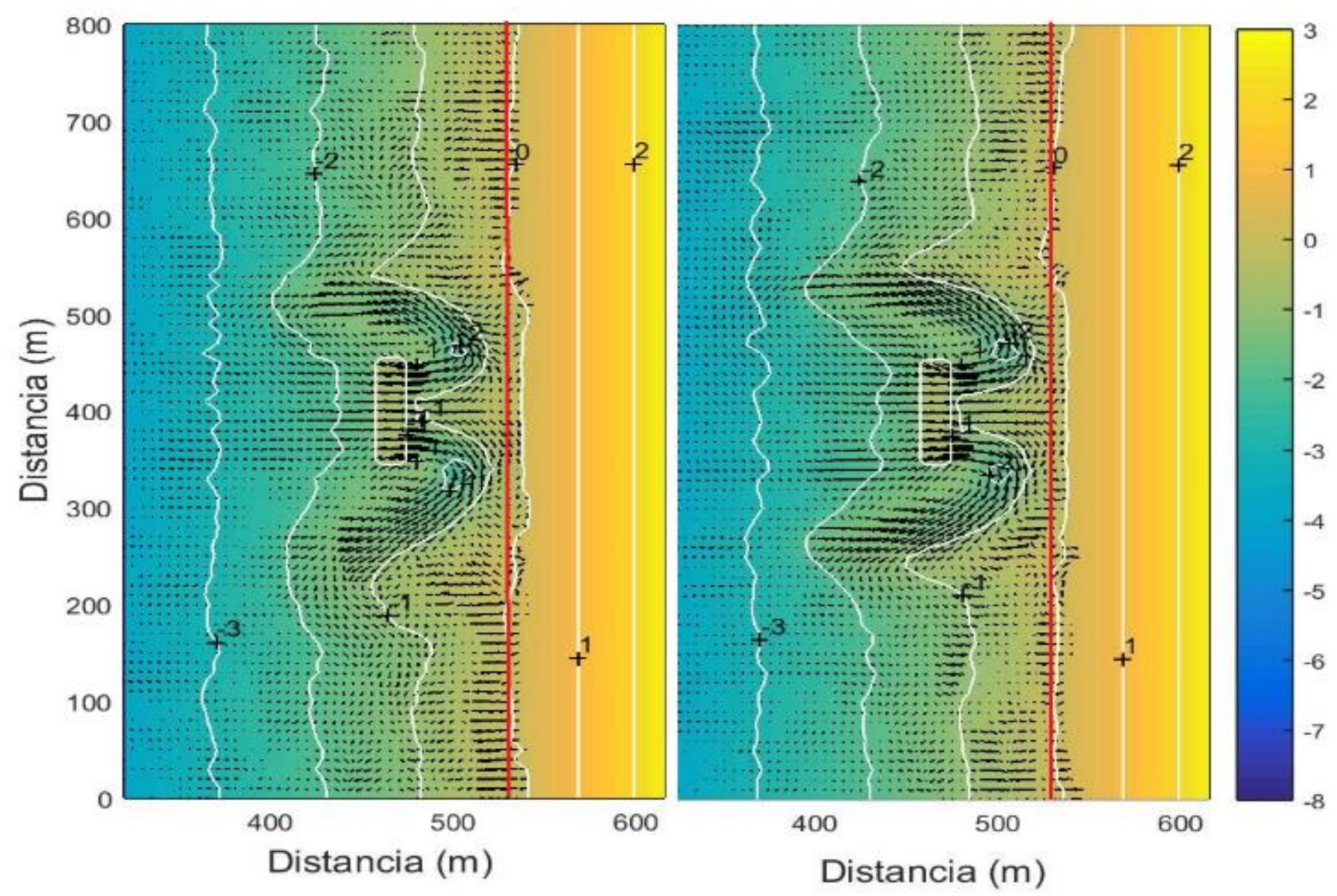

Figura 16. Patrones de corrientes para rompeolas de $100 \mathrm{~m}$ de longitud y $10 \mathrm{~m}$ de ancho ubicado a $60 \mathrm{~m}$ de la costa con sumergencia de -0.5 m. Izquierda: oleaje perpendicular; derecha: oleaje oblicuo. 
Tecnología y

Ciencias $\stackrel{\Xi}{\triangleleft}$ gua
2022, Instituto Mexicano de Tecnología del Agua

Open Access bajo la licencia CC BY-NC-SA 4.0

(https://creativecommons.org/licenses/by-nc-sa/4.0/)
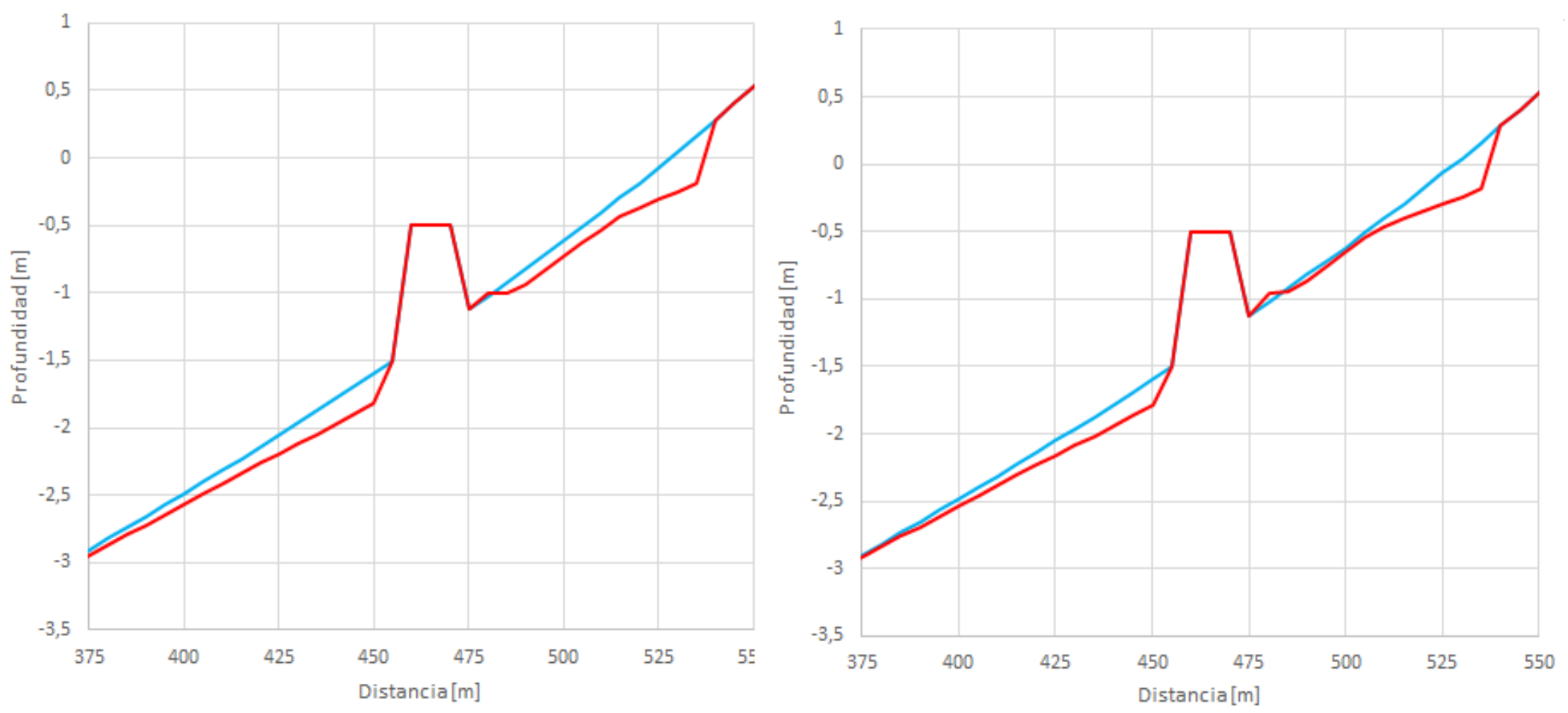

Figura 17. Evolución del fondo marino para rompeolas de 100 m de longitud y $10 \mathrm{~m}$ de ancho ubicado a $60 \mathrm{~m}$ de la costa con sumergencia de -0.5 m. Izquierda: oleaje perpendicular; derecha: oleaje oblicuo.

\section{Efecto de la distancia a la costa del rompeolas sumergido $(X b)$}

El análisis se realizó variando las distancias a la línea de costa, ubicando Ios rompeolas a 30,60, 90, 120, 150, 180, 210, 240, 270 y 300 m de 
Tecnología y

Ciencias $₫$ Agua
2022, Instituto Mexicano de Tecnología del Agua

Open Access bajo la licencia CCBY-NC-SA 4.0

(https://creativecommons.org/licenses/by-nc-sa/4.0/)

separación. El efecto que tiene la distancia de colocación del rompeolas sobre la altura media cuadrática de las olas de gravedad y sobre el coeficiente de transmisión se muestra en la Figura 18, que disminuye al alejarse el rompeolas de la costa, correspondiendo los menores valores en todos los casos a los rompeolas de $20 \mathrm{~m}$ de ancho.

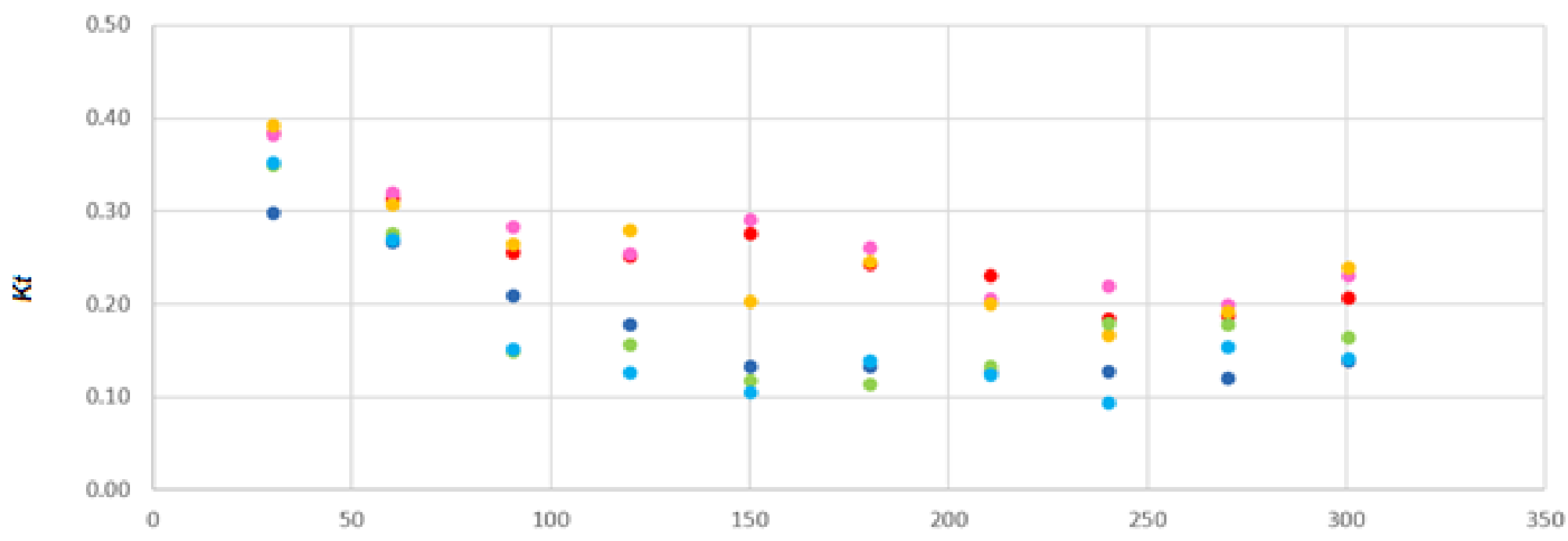

Distancia a la costa Xb (m)

- Longitud $100 \mathrm{~m}$ Ancho $10 \mathrm{~m}$

- Longitud $100 \mathrm{~m}$ Ancho $20 \mathrm{~m}$
- Longitud $200 \mathrm{~m}$ Ancho $10 \mathrm{~m}$

- Longitud $200 \mathrm{~m}$ Ancho $20 \mathrm{~m}$
Longitud $300 \mathrm{~m}$ Ancho $10 \mathrm{~m}$

- Longitud $300 \mathrm{~m}$ Ancho $20 \mathrm{~m}$

Figura 18. Coeficiente de transmisión en función a la distancia de colocación de los rompeolas respecto a la costa para rompeolas de 100

m, $200 \mathrm{~m}$ y $300 \mathrm{~m}$ de longitud y ancho de corona de $10 \mathrm{~m}$ y $20 \mathrm{~m}$.

La Figura 19 refleja los patrones de velocidad y circulación de las corrientes para las ubicaciones cercanas a la costa, donde se presentan 
Tecnología y

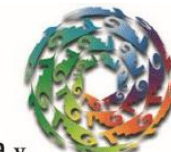

Ciencias $\approx$ Agua
2022, Instituto Mexicano de Tecnología del Agua

Open Access bajo la licencia CC BY-NC-SA 4.0

(https://creativecommons.org/licenses/by-nc-sa/4.0/)

patrones de dos celdas erosivos. En la medida que se aleja el rompeolas de la costa, se comienzan a presentar patrones acumulativos de cuatro celdas y un avance de la línea costera con respecto a su posición inicial, destacada por la línea de color rojo, comportamientos descritos por Ranasinghe et al. (2010).
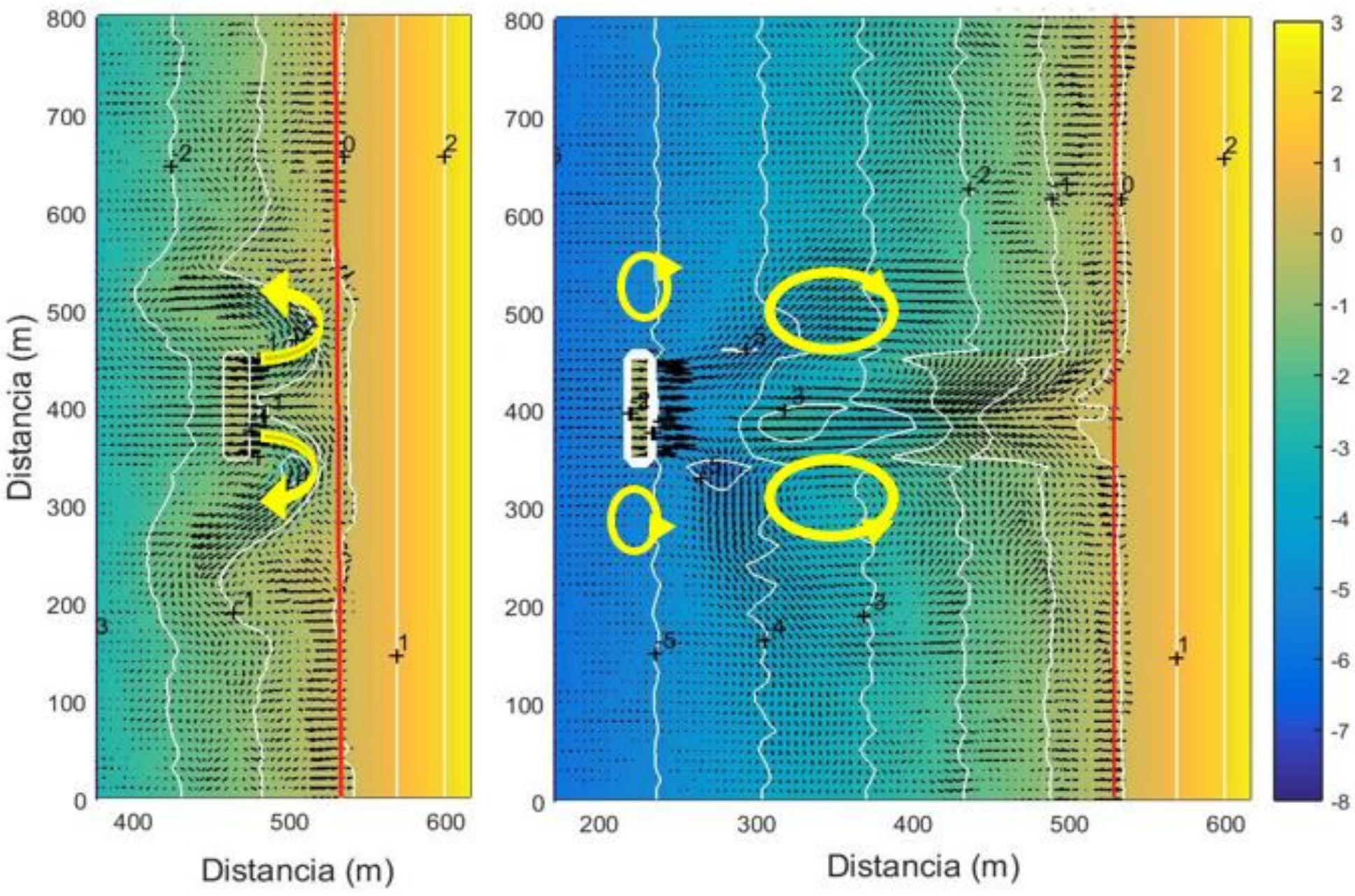
Figura 19. Circulación de las corrientes. Izquierda: rompeolas a $90 \mathrm{~m}$ de distancia y patrones de dos celdas erosivos; derecha: rompeolas a $300 \mathrm{~m}$ de distancia y patrones de cuatro celdas acumulativos.

El comportamiento de los patrones de velocidad del flujo se confirma en la representación del transporte de sedimento dado en la Figura 20, que concuerda con los cambios morfológicos que sufre el fondo y con la posición que adopta la línea de costa. La evolución del fondo marino con el pasar del tiempo se refleja en la Figura 21, donde la imagen izquierda, correspondiente al rompeolas ubicado a $90 \mathrm{~m}$ de la costa, muestra la erosión que sufre la playa; mientras que la imagen derecha, rompeolas que se encuentra a $300 \mathrm{~m}$ de separación de la costa, muestra la acumulación de sedimentos y el avance alcanzado. 
Tecnología y

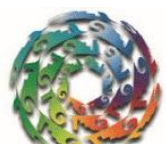

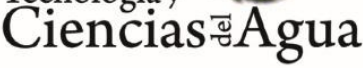

2022, Instituto Mexicano de Tecnología del Agua

Open Access bajo la licencia CC BY-NC-SA 4.0

(https://creativecommons.org/licenses/by-nc-sa/4.0/)
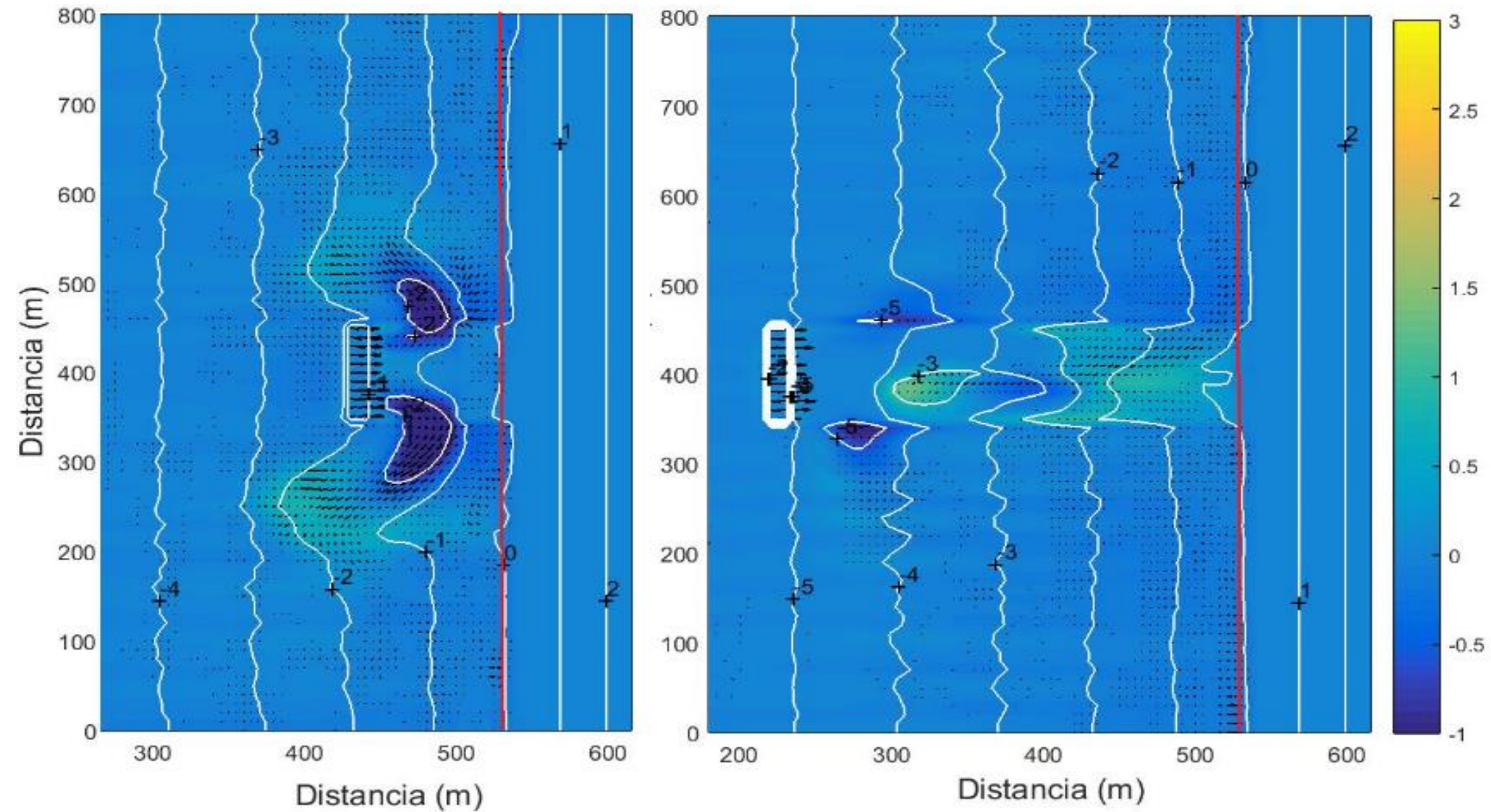

Figura 20. Transporte de sedimento para rompeolas de $10 \mathrm{~m}$ de ancho. Izquierda, rompeolas a $90 \mathrm{~m}$ de distancia de la costa y derecha a 300

$\mathrm{m}$. 
Tecnología y

Ciencias $\approx$ Agua

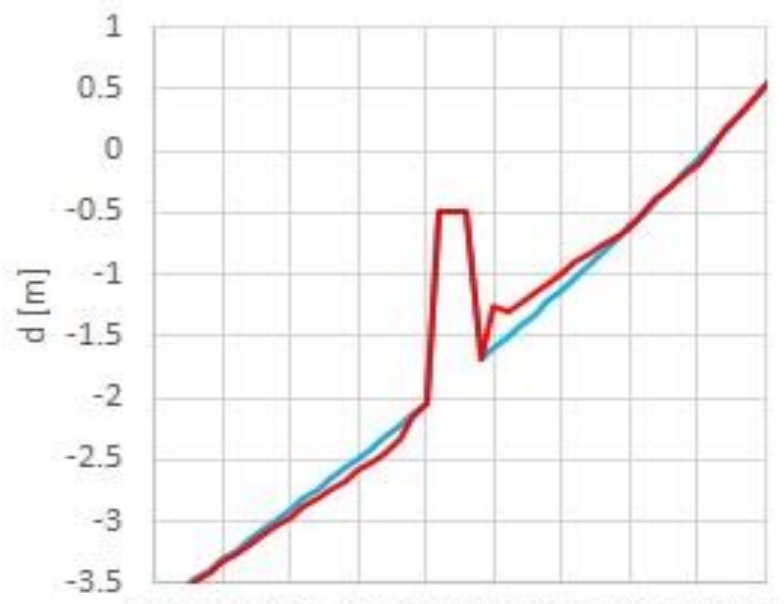

325350375400425450475500525550

Distancia [m]

fondo in icial

fondo final a 100 días
2022, Instituto Mexicano de Tecnología del Agua

Open Access bajo la licencia CCBY-NC-SA 4.0

(https://creativecommons.org/licenses/by-nc-sa/4.0/)

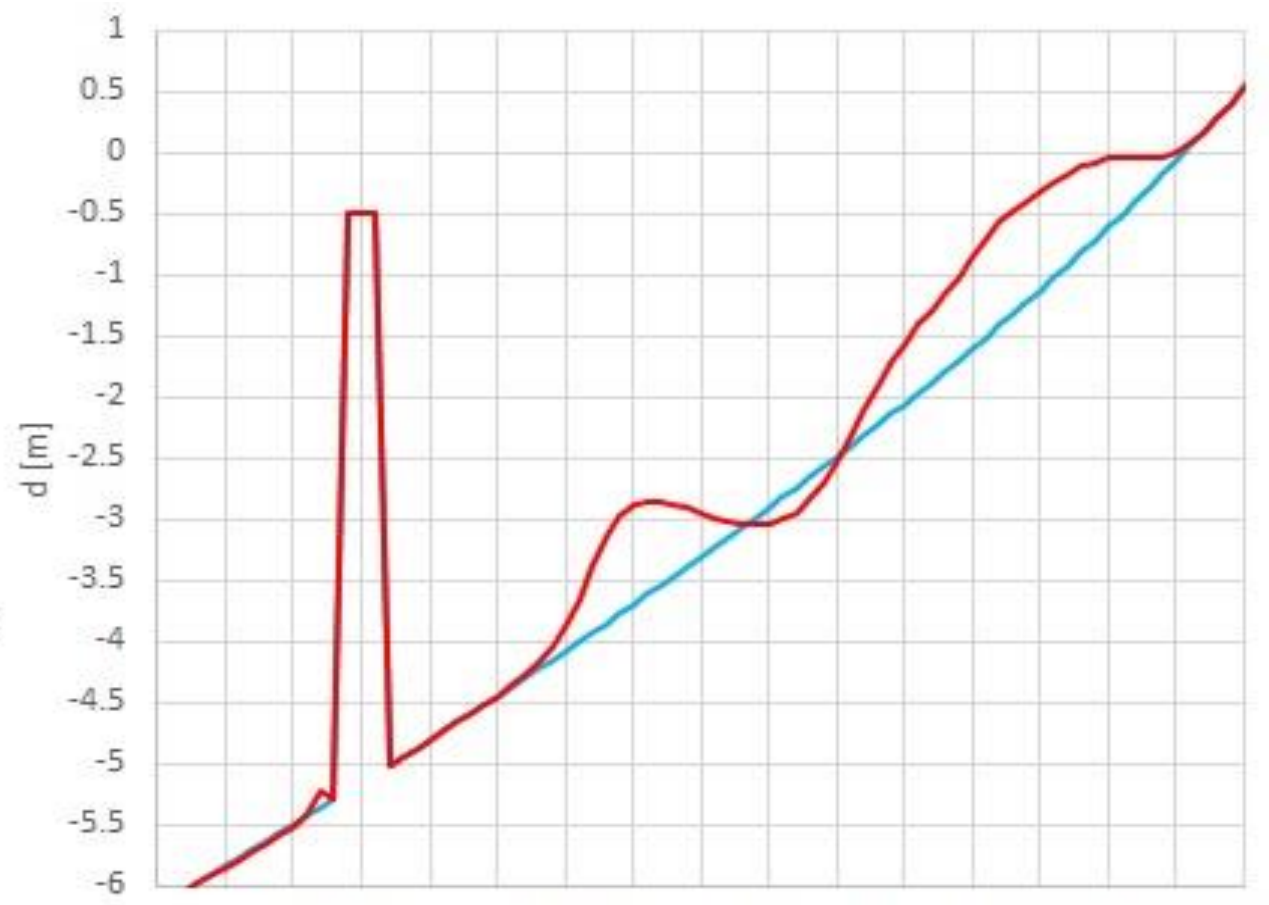

150175200225250275300325350375400425450475500525550 Distancia [m]

Figura 21. Comportamiento del fondo para rompeolas de $10 \mathrm{~m}$ de ancho de cresta ubicado a $90 \mathrm{~m}$ de la costa (izquierda) y a $300 \mathrm{~m}$ (derecha).

La Figura 22 indica los resultados del movimiento de la línea de costa (erosión/acreción) obtenidos en función de la ubicación del rompeolas tanto para el oleaje con incidencia perpendicular a la costa como para el oleaje con incidencia oblicua. 
2022, Instituto Mexicano de Tecnología del Agua

Tecnología y

Open Access bajo la licencia CC BY-NC-SA 4.0

(https://creativecommons.org/licenses/by-nc-sa/4.0/)

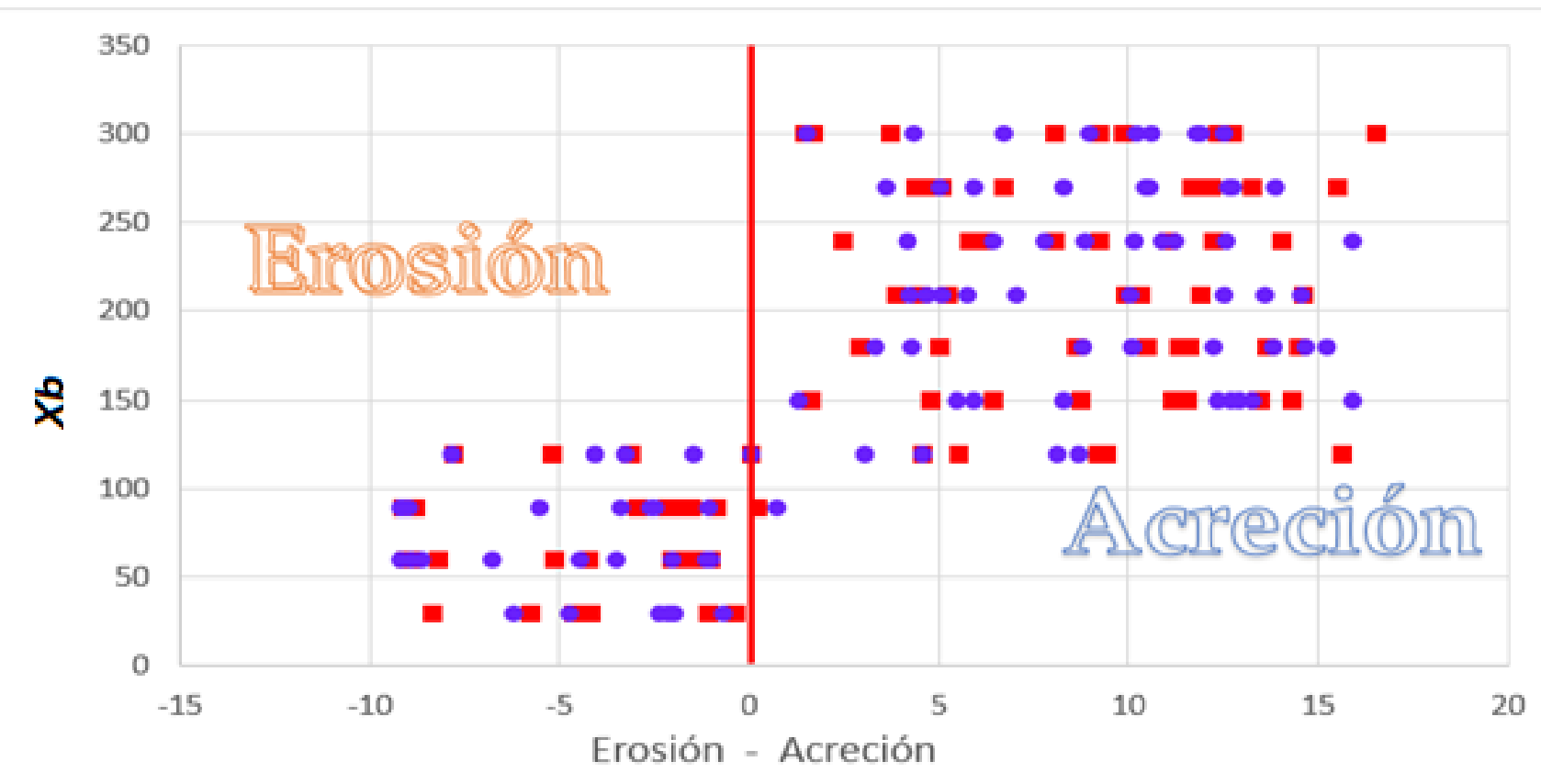

Oleaje normal a la costa $\quad$ Oleaje oblicuo a la costa

Figura 22. Respuesta de la costa (erosión/acreción) en función de la distancia de colocación del rompeolas.

La Figura 23 muestra cómo para las posiciones cercanas hasta los $100 \mathrm{~m}$ de distancia, la línea costera retrocede en todas las longitudes de rompeolas estudiadas, lo que se destaca con un cuadro rojo. A partir de los $120 \mathrm{~m}$ de separación del rompeolas de la costa se comienzan a observar avances en la línea costera, aunque también se manifiestan procesos erosivos, comportándose como una zona de transición (cuadro de color verde). Para las posiciones mayores de $150 \mathrm{~m}$ siempre se produce acumulación de sedimentos en la playa, que llegan a alcanzar hasta los $18 \mathrm{~m}$ de ancho y se delimitan en color amarillo. 
Tecnología y

Ciencias $₫$ Agua
2022, Instituto Mexicano de Tecnología del Agua

Open Access bajo la licencia CC BY-NC-SA 4.0

(https://creativecommons.org/licenses/by-nc-sa/4.0/)

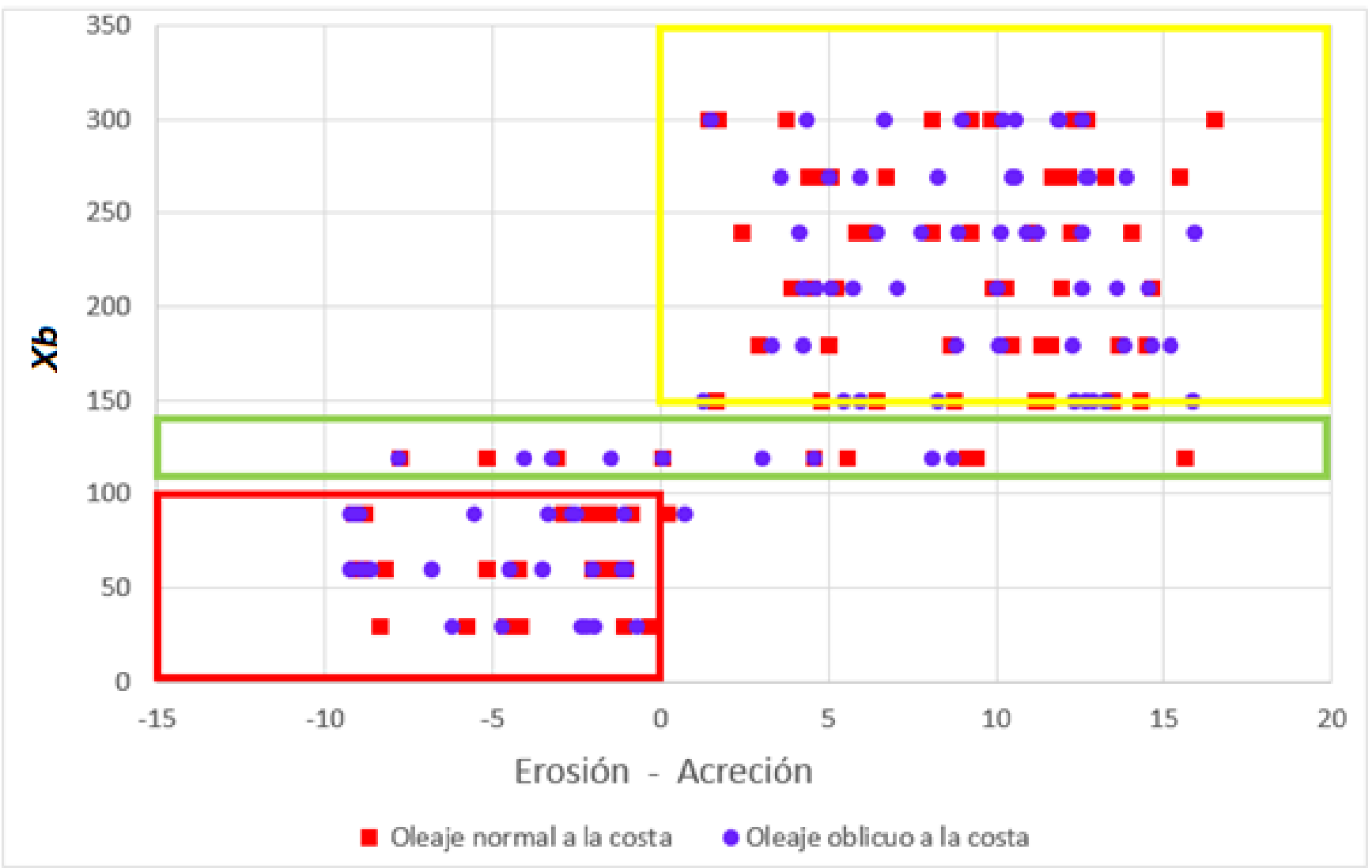

Figura 23. Respuesta de la costa (erosión/acreción) en función de la distancia de colocación del rompeolas y su delimitación.

Las simulaciones variando la distancia del rompeolas a la costa muestran la presencia de patrones de circulación de dos celdas erosivos o patrones de cuatro celdas acumulativos, que es uno de los parámetros dominantes que determinan el modo de respuesta de la costa.

La Figura 24, Figura 25 y Figura 26 evidencian la respuesta morfológica de la playa a través de la longitud del saliente conformado 
Tecnología y

Ciencias $\stackrel{\unlhd}{\unlhd}$ gua
2022, Instituto Mexicano de Tecnología del Agua

Open Access bajo la licencia CC BY-NC-SA 4.0

(https://creativecommons.org/licenses/by-nc-sa/4.0/)

$(X s)$, la que varía en dependencia de la longitud del rompeolas $(L b)$ y de la distancia con respecto a la costa original $(X b)$, a través del parámetro adimensional $L b / X b$, que constituyen los principales parámetros de diseño que rigen el comportamiento funcional de estas obras.

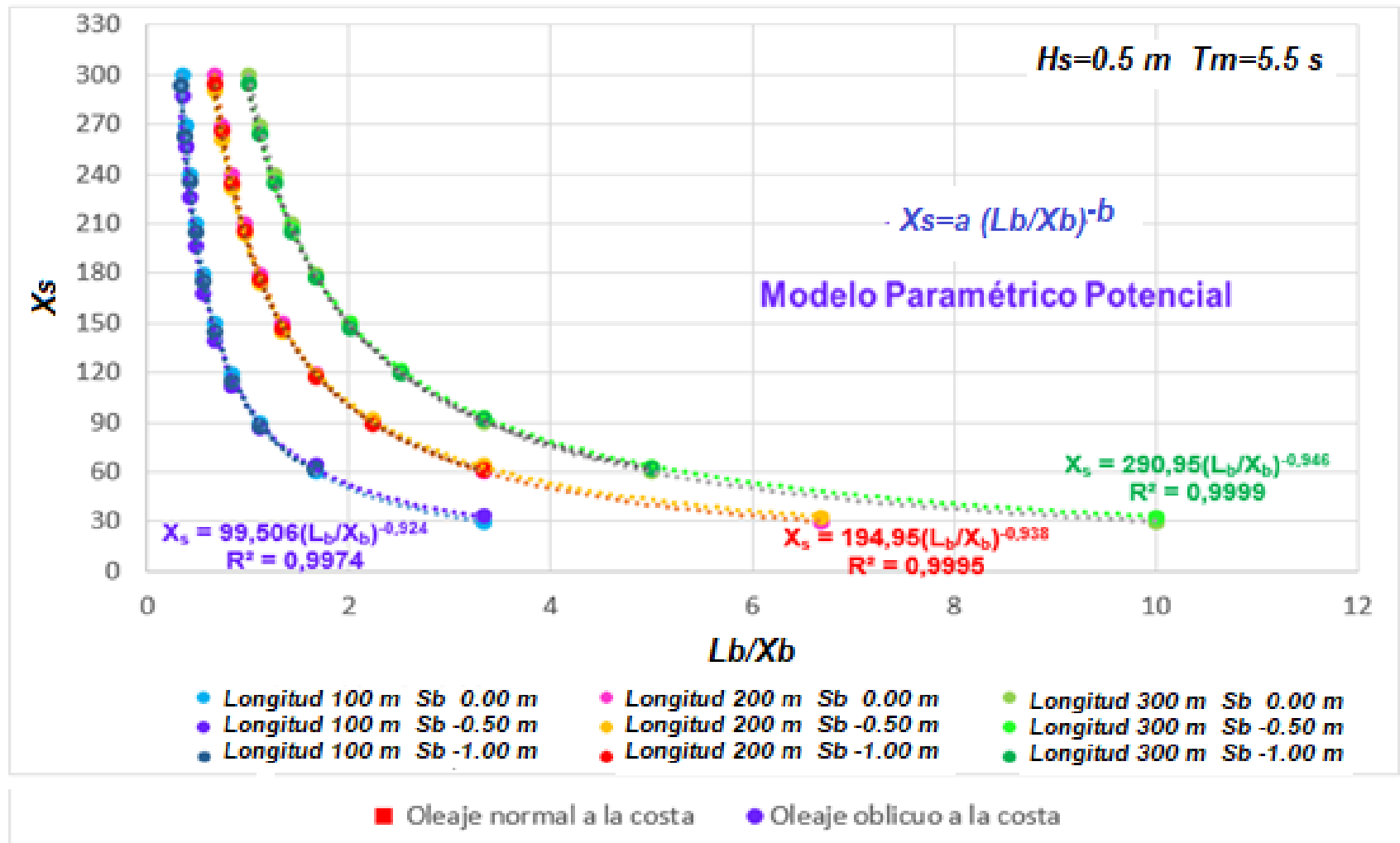

Figura 24. Relación longitud del rompeolas/distancia a la costa inicial vs. distancia a la línea de costa resultante $(X s) . H s=0.5 \mathrm{~m}, \mathrm{Tm}=5.5 \mathrm{~s}$. 
Tecnología y

Ciencias $\mathrm{v}$ Agua
2022, Instituto Mexicano de Tecnología del Agua

Open Access bajo la licencia CC BY-NC-SA 4.0

(https://creativecommons.org/licenses/by-nc-sa/4.0/)

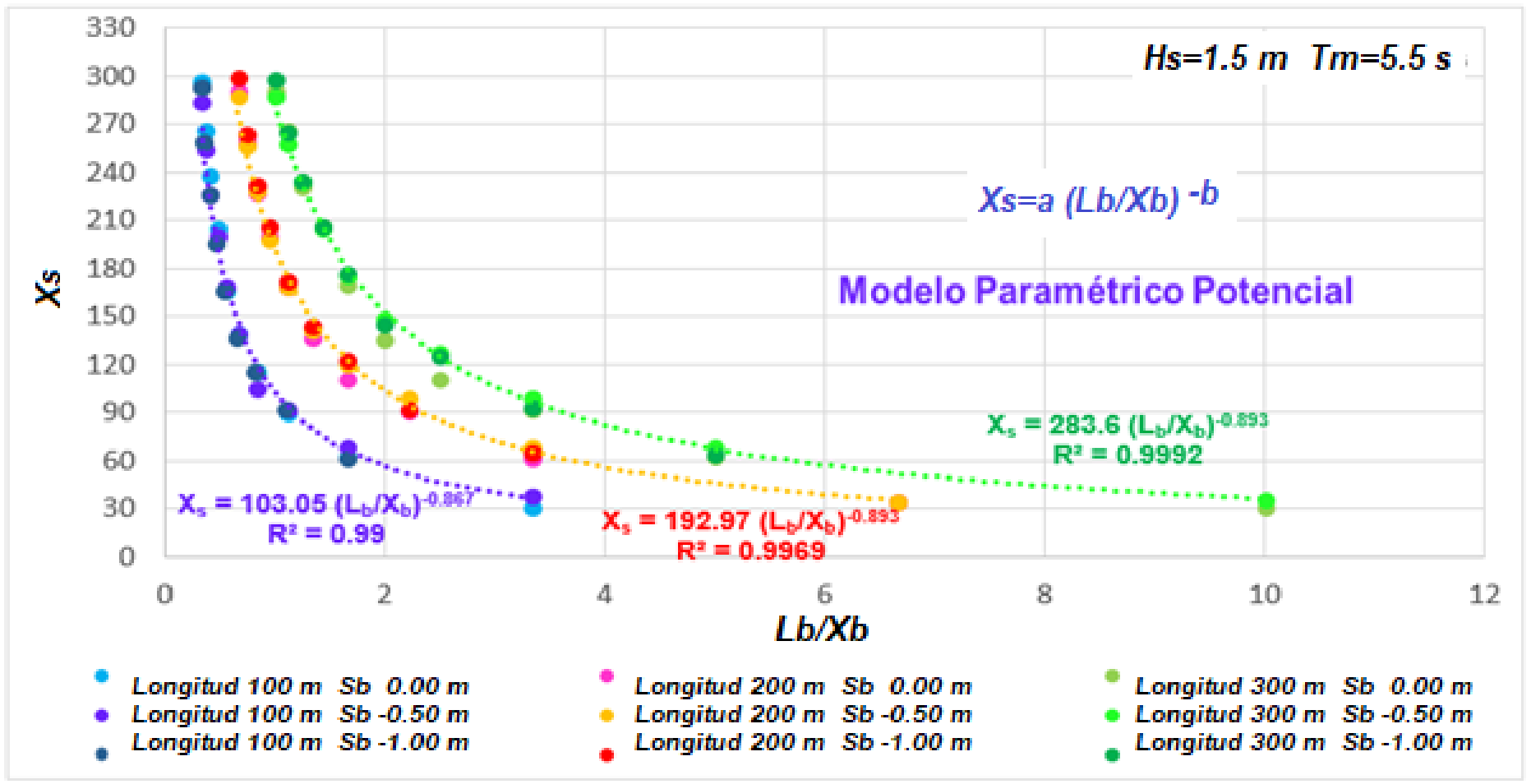

Figura 25. Relación Longitud del rompeolas/distancia a la costa inicial $v s$. distancia a la línea de costa resultante $(X s) . H s=1.5 \mathrm{~m}, \mathrm{Tm}=5.5 \mathrm{~s}$. 
Tecnología y

Ciencias $\approx$ Agua
2022, Instituto Mexicano de Tecnología del Agua

Open Access bajo la licencia CCBY-NC-SA 4.0

(https://creativecommons.org/licenses/by-nc-sa/4.0/)

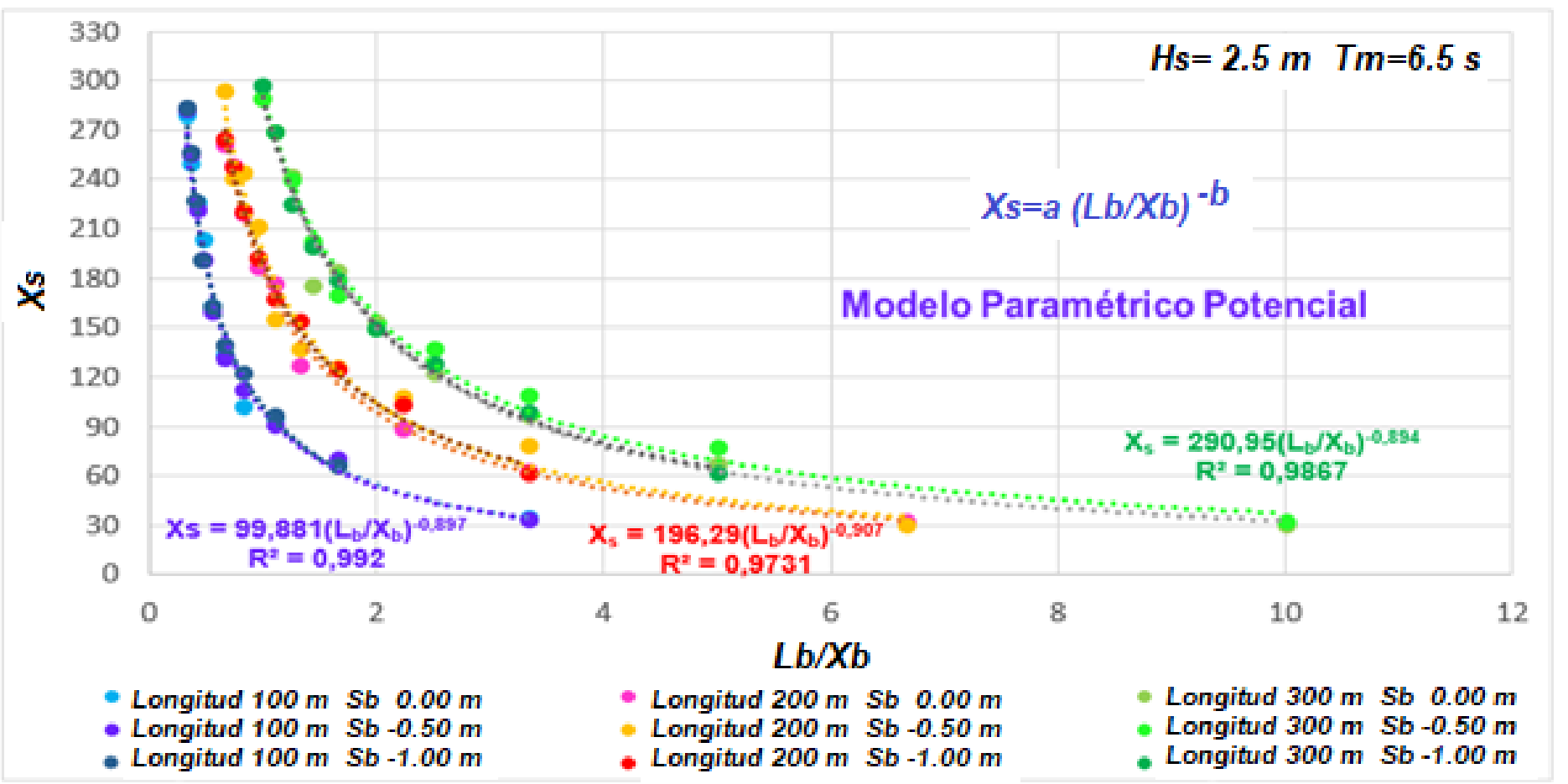

Figura 26. Relación Longitud del rompeolas/distancia a la costa inicial $v s$. distancia a la línea de costa resultante $(X s) . H s=2.5 \mathrm{~m}, T m=6.5 \mathrm{~s}$.

Los resultados obtenidos en la investigación permitieron establecer relaciones predictivas sobre el comportamiento de la línea costera (erosión/acreción) en función del parámetro adimensional $(L b / X b)$, proponiendo un modelo paramétrico de tipo potencial que responde a la formulación general:

$X_{s}=a\left(L_{b} / X_{b}\right)^{-b}$ 
Tecnología y

Ciencias $₫$ Agua
2022, Instituto Mexicano de Tecnología del Agua

Open Access bajo la licencia CC BY-NC-SA 4.0

(https://creativecommons.org/licenses/by-nc-sa/4.0/)

El parámetro $a$ y el exponente $b$ se recogen en la Tabla 11, Tabla 12 y Tabla 13.

Tabla 11. Parámetro $a$ y exponente $b$ de la función potencial para rompeolas de longitud $L b=100 \mathrm{~m}$.

\begin{tabular}{|c|c|c|c|}
\hline Hidrodinámicas & $\begin{array}{c}\text { Sumergencias } \\
\text { (m) }\end{array}$ & $\mathbf{a}$ & $\boldsymbol{b}$ \\
\hline \multirow{3}{*}{$\begin{array}{l}\mathrm{Hs}=0.5 \mathrm{~m} \\
\mathrm{Tm}=5.5 \mathrm{~s}\end{array}$} & 0.00 & 100 & -1 \\
\hline & -0.50 & 99.50 & -0.924 \\
\hline & -1.00 & 98.91 & -0.978 \\
\hline \multirow{3}{*}{$\begin{array}{l}H s=1.5 \mathrm{~m} \\
T m=5.5 \mathrm{~s}\end{array}$} & 0.00 & 98.98 & -0.970 \\
\hline & -0.50 & 103.05 & -0.867 \\
\hline & -1.00 & 97.75 & -0.956 \\
\hline \multirow{3}{*}{$\begin{array}{l}H s=2.5 \mathrm{~m} \\
T m=6.5 \mathrm{~s}\end{array}$} & 0.00 & 100.87 & -0.888 \\
\hline & -0.50 & 99.88 & -0.897 \\
\hline & -1.00 & 102.11 & -0.893 \\
\hline
\end{tabular}

Tabla 12. Parámetro $a$ y exponente $b$ de la función potencial para rompeolas de longitud $\angle b=200 \mathrm{~m}$.

\begin{tabular}{|c|c|c|c|}
\hline Hidrodinámicas & $\begin{array}{c}\text { Sumergencias } \\
\mathbf{( m )}\end{array}$ & a & b \\
\hline $\mathrm{Hs}=0.5 \mathrm{~m}$ & 0.00 & 200 & -1 \\
\hline
\end{tabular}


Tecnología y

Ciencias $\cong$ Agua
2022, Instituto Mexicano de Tecnología del Agua

Open Access bajo la licencia CC BY-NC-SA 4.0

(https://creativecommons.org/licenses/by-nc-sa/4.0/)

\begin{tabular}{|c|c|c|c|}
\hline \multirow{2}{*}{$\mathrm{Tm}=5.5 \mathrm{~s}$} & -0.50 & 194.95 & -0.938 \\
\cline { 2 - 4 } & -1.00 & 196.51 & -0.978 \\
\hline \multirow{2}{*}{$\mathrm{Hs}=1.5 \mathrm{~m}$} & 0.00 & 189.68 & -0.928 \\
\cline { 2 - 4 } $\mathrm{Tm}=5.5 \mathrm{~s}$ & -0.50 & 192.97 & -0.893 \\
\cline { 2 - 4 } & -1.00 & 196.40 & -0.939 \\
\hline \multirow{2}{*}{$\mathrm{Hs}=2.5 \mathrm{~m}$} & 0.00 & 184.26 & -0.902 \\
\cline { 2 - 4 } $\mathrm{Tm}=6.5 \mathrm{~s}$ & -0.50 & 196.29 & -0.973 \\
\cline { 2 - 4 } & -1.00 & 189.60 & -0.865 \\
\hline
\end{tabular}

Tabla 13. Parámetro $a$ y exponente $b$ de la función potencial para rompeolas de longitud $L b=300 \mathrm{~m}$.

\begin{tabular}{|c|c|c|c|}
\hline Hidrodinámicas & $\begin{array}{c}\text { Sumergencias } \\
(\mathbf{m})\end{array}$ & $\boldsymbol{a}$ & $\boldsymbol{b}$ \\
\hline \multirow{2}{*}{$\begin{array}{c}\mathrm{Hs}=0.5 \mathrm{~m} \\
\mathrm{Tm}=5.5 \mathrm{~s}\end{array}$} & 0.00 & 300 & -1.00 \\
\cline { 2 - 4 } & -0.50 & 290.95 & -0.946 \\
\hline \multirow{2}{*}{$\mathrm{Hs}=1.5 \mathrm{~m}$} & -1.00 & 291.63 & -0.965 \\
\cline { 2 - 4 } $\mathrm{Tm}=5.5 \mathrm{~s}$ & 0.00 & 285.06 & -0.971 \\
\cline { 2 - 4 } & -0.50 & 283.60 & -0.893 \\
\hline $\mathrm{Hs}=2.5 \mathrm{~m}$ & -1.00 & 290.52 & -0.945 \\
\cline { 2 - 4 } $\mathrm{Tm}=6.5 \mathrm{~s}$ & -0.00 & 290.18 & -0.948 \\
\cline { 2 - 4 } & -0.50 & 290.95 & -0.986 \\
\hline
\end{tabular}




\begin{tabular}{|l|l|l|l|}
\hline & -1.00 & 289.76 & -0.932 \\
\hline
\end{tabular}

Como resultado de carácter práctico para el empleo de las relaciones predictivas se elaboró una metodología que consta de cuatro pasos, utilizando las gráficas de las Figuras 24, Figura 25 o Figura 26 :

1. Calcular la relación $L b / X b$.

2. Plotear la relación $L b / X b$ (eje de las abscisas) en la gráfica de la Figura 24, Figura 25 o Figura 26 según corresponda con el oleaje y la sumergencia definidos como datos de partida.

3. Obtener por el intercepto del eje de las abscisas con la curva correspondiente a la longitud de rompeolas el valor Xs (distancia entre la línea de costa formada y el rompeolas) en el eje de las ordenadas.

4. Determinar la respuesta esperada de la costa restando de la distancia a la costa inicial $X b$ establecida en el diseño el valor $X s$ obtenido de la gráfica. Respuesta (erosión o acreción) $=X b-X s$.

La aplicación de la metodología se presenta en el caso de estudio del hotel Meliá Varadero. Este hotel se ubica sobre un macizo rocoso, a ambos lados se extienden zonas de terraza baja con longitudes de 200 $\mathrm{m}, \mathrm{y}$ altitudes entre $1.6 \mathrm{~m}$ y $2.5 \mathrm{~m}$, que dificultan el acceso a la playa y limitan su uso como zona de baño (Figura 27). 


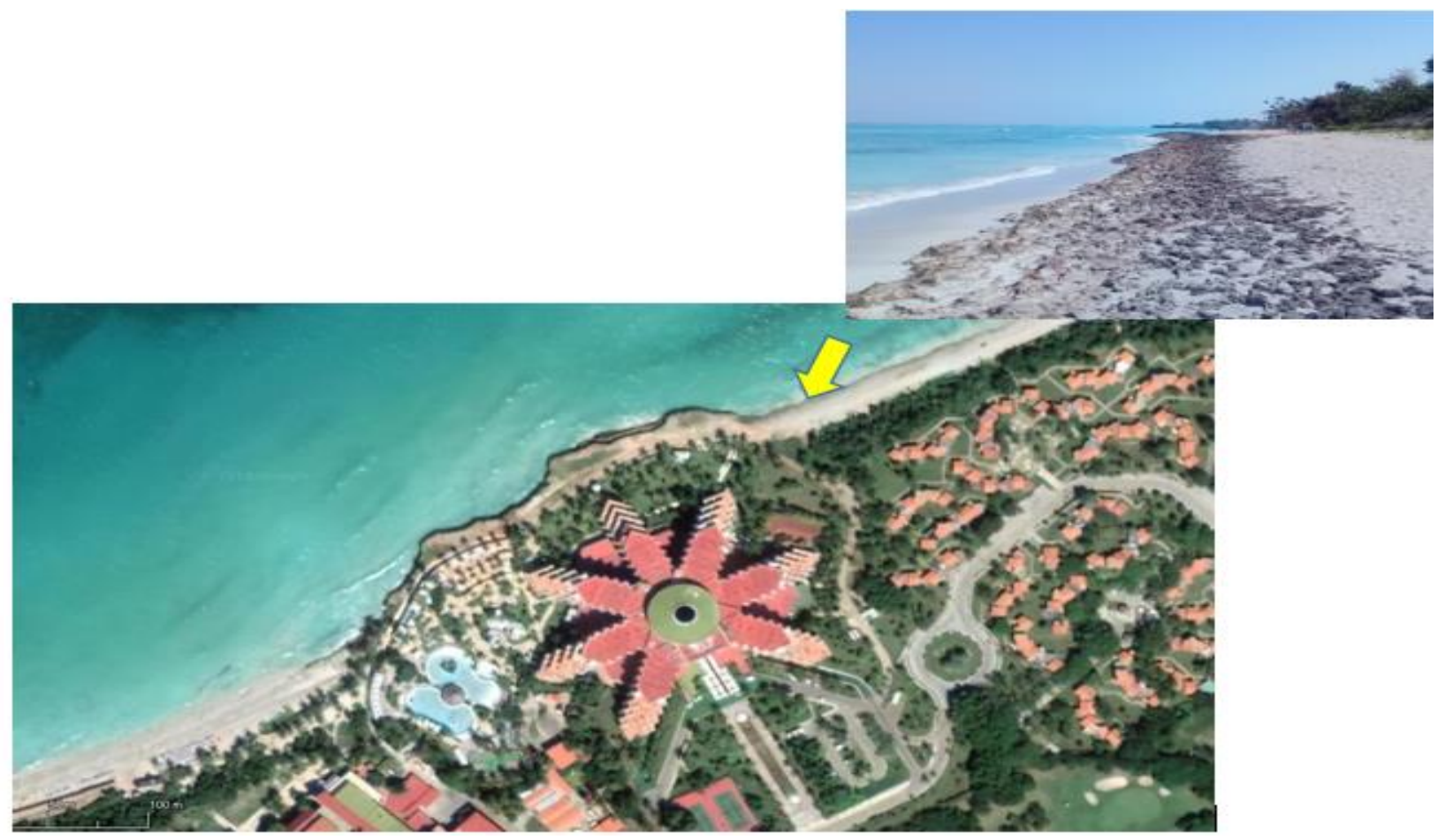

Figura 27. Ubicación del hotel Meliá Varadero.

La ubicación de rompeolas sumergidos de $100 \mathrm{~m}$ de longitud constituye una solución viable para estabilizar la playa. Se propone colocarlo separado de la costa a una distancia de $150 \mathrm{~m}$ con sumergencia de $-0.50 \mathrm{~m}$ y un ancho de coronación de $10 \mathrm{~m}$. Se establecen los valores de altura de ola significativa $H s=1.5 \mathrm{~m}$ y periodo medio del oleaje $T m=$ $5.5 \mathrm{~s}$.

1. Se calcula la relación $L b / X b=100 \mathrm{~m} / 150 \mathrm{~m}=0.666$.

2. Se plotea la relación $L b / X b=0.666$ en la gráfica de la Figura 25 y se obtiene el intercepto con la curva de longitud $100 \mathrm{~m}$.

3. Valor del intercepto en el eje de las ordenadas $X s=138 \mathrm{~m}$. 
4. Como la distancia inicial a la costa $X b$ se propone de $150 \mathrm{~m}$, con esta ubicación la respuesta esperada de la línea de costa se determina así: Respuesta $=150 \mathrm{~m}-138 \mathrm{~m}=12 \mathrm{~m}$.

La línea de costa experimentará un proceso acumulativo con la formación de un saliente de $12 \mathrm{~m}$ de ancho, como se observa en la Figura 28.

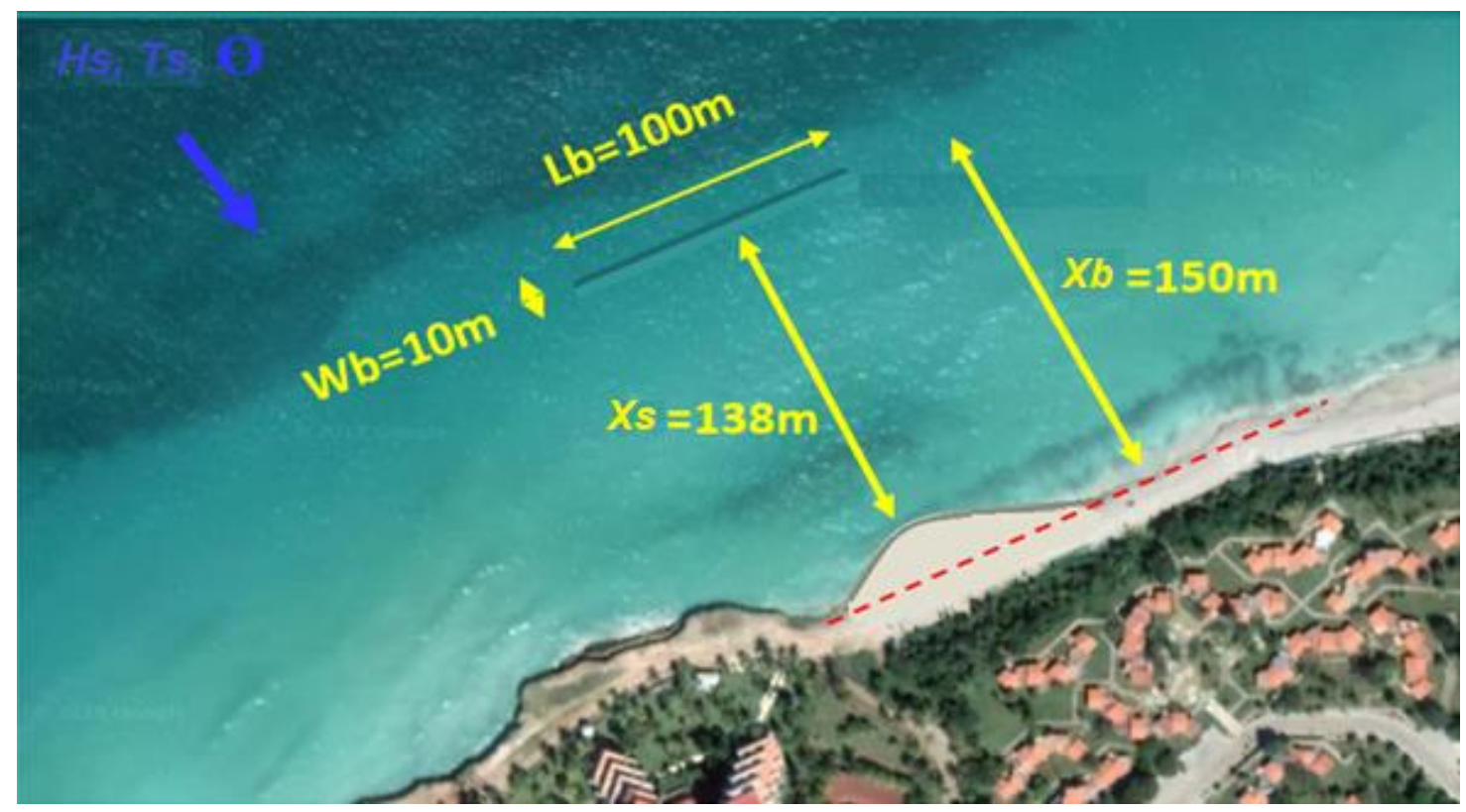

Figura 28. Formación en la playa de un saliente de $12 \mathrm{~m}$ de ancho debido a la ubicación de un rompeolas sumergido de $100 \mathrm{~m}$ de longitud.

\section{Conclusiones}


El comportamiento de las corrientes y, por tanto, la forma en que cambia el fondo es similar para rompeolas con diferentes longitudes. La zona de influencia aumenta al incrementarse la longitud del rompeolas.

Con el aumento del ancho de cresta, el coeficiente de transmisión disminuye y los niveles de agua en la zona abrigada del rompeolas decrecen, siendo más efectivo en la disipación de la altura de olas.

La ubicación de los rompeolas con respecto a la costa presenta una fuerte relación con la respuesta morfológica de la playa; se destacan patrones de tipo erosivo o acumulativo.

La sumergencia es un parámetro íntimamente relacionado con el coeficiente de transmisión y con la morfología de la playa. Al aumentar la sumergencia a niveles de $-1.00 \mathrm{~m}$, el efecto disipador del rompeolas disminuye, por lo que no se recomienda el empleo de sumergencias con valores mayores a $-1.00 \mathrm{~m}$.

Se evidencia que la oblicuidad del oleaje no ejerce influencia significativa en el modo de respuesta de la costa ni en la transmisión del oleaje; se obtienen resultados muy similares a los alcanzados con el oleaje perpendicular a la costa.

Se determina que los parámetros de diseño funcional de los rompeolas sumergidos que más influyen en la respuesta de la playa son la distancia a la costa, la longitud del rompeolas y la sumergencia. 
Se presentan relaciones predictivas en forma de gráficas, que responden a un modelo paramétrico de tipo potencial, donde puede conocerse la evolución que tendrá la línea costera en función de parámetros adimensionales; se elaboró una metodología como resultado de carácter práctico para el diseño funcional de los rompeolas sumergidos.

\section{Agradecimientos}

Los autores desean agradecer a todas aquellas personas que han permitido, ayudado y colaborado con la obtención de los resultados referidos en el presente trabajo.

\section{Referencias}

Córdova, L., Hernández, K., \& Benítez, H. (2017). Modelación matemática de procesos morfológicos en playas con rompeolas sumergidos. Ingeniería Hidráulica y Ambiental, 38(1), 59-71.

Calabrese, M., Vicinanza, D., \& Buccino, M. (2008). 2D Wave setup behind submerged breakwaters. Ocean Engineering Journal, 35, 10151028.

García, C. (2005). Actuaciones para el control de la erosión en playas biogénicas. El caso de la playa de Varadero (tesis presentada en opción al grado científico de Doctor en Ciencias Geográficas), Instituto de Geografía Tropical, La Habana, Cuba. 
Hernández, K., \& Córdova, L. (2015). Simulación matemática de la interacción oleaje-estructuras de protección costera. Ingeniería Hidráulica y Ambiental, 36(3), 74-87.

Hernández, K., \& Córdova, L. (2016). Calibración y validación de un modelo matemático para la simulación de los cambios morfológicos durante eventos extremos en una playa del Caribe. Tecnología y ciencias del agua, 7(3), 135-153. DOI: 10.24850/j-tyca-imta

Makris, V., \& Memos, C. (2007). Wave transmission over submerged breakwaters: performance of formulae and models. Proceedings of the Sixteenth International Offshore and Polar Engineering Conference, Lisbon, Portugal.

Papadopoulos, D. (2012). Scour below the toe of breakwaters (thesis submitted for the degree of Master of Science in Hydraulic Engineering), Delf University of Technology, The Netherlands.

Ranasinghe, R., Larson, M., \& Savioli, J. (2010). Shoreline response to a single shore- parallel submerged breakwater. Coastal Engineering, (57),1006-1017. DOI: 10.1016/j.coastaleng.2010.06.002

Roelvink, D., Reniers, A., van Dongeren, A., van Thiel-de-Vries, J., McCall, R., \& Lescinski, J. (2009). Modelling storm impacts on beaches, dunes and barrier islands. Coastal Engineering, 56, 1133-1152. DOI: $10.1016 /$ j.costaleng.2009.08.006

Vanlishout, V. (2008). Oblique wave transmission through rough impermeable rubble mound submerged breakwaters (thesis of the Master of Science degree in Civil Engineering), Ghent University, The Netherlands. 